\title{
Structure and Hardness of Ausformed or Deformed \\ Ferrous Martensites"
}

\author{
By Imao Tamura**
}

\section{Synopsis}

This paper is a review of several researches on ausformed or deformed martensites carried out mainly in the author's former laboratory at Osaka University.

Some amount of carbon content in steel zias essential for the strengthening of steel by ausforming. In ausformed martensite, dislocation density was very high. Effect of stacking fault energy of austenite on hardening of martensite by ausforming was discussed and a model that screened dislocations by austenite-martensite interface were inherited by martensite, was proposed for strengthening mechanism of ausformed martensite without reducing ductility.

The resistance to hardness decrease by tempering was increased by ausforming because the temperature at which dislocations were diminished became higher and the growth of carbide precipitates was delayed.

In high carbon high alloy tool steels, strength and especially ductility were increased in the steel containing strong carbide forming elements, especially Mo, because their carbides precipitated before tempering.

When the twinned martensite was deformed by twinning, strainsoftening was induced by detwinning of transformation twins. After such softening, strain-hardening rapidly occurred as the degree of deformation was increased. When the martensite was deformed by slip, usual strain-hardening was observed. Also, the other important problems were discussed.

\section{Introduction}

Ausforming of steel has progressively become an attractive problem theoretically and practically, among several methods of thermo-mechanical treatment, because the ausforming markedly strengthens steels without reducing their ductility. Also, deformation modes and strengthening mechanism of martensite by deformation are important and interesting problems.

The author and his coworkers have researched on these problems mainly by means of transmission electron microscopy, since $1961 .{ }^{1)-7)}$ This paper is a summarized report of these researches. The main part of these researches carried out in the author's former laboratory, The Institute of Scientific and Industrial Research, Osaka University.

\section{Structure and Hardness of Ausformed Martensite}

1. Fe-Ni and Fe-Ni-C Alloys (Austenite of High Stacking Fault Energy) ${ }^{11}$

$\mathrm{Fe}-29.7 \% \mathrm{Ni}(0.006 \% \mathrm{C})$ and $\mathrm{Fe}-29.7 \% \mathrm{Ni}-0.42 \% \mathrm{C}$ alloys were prepared by vacuum melting and homogenizing annealing, and rolled into sheet specimen. The specimens were austenitized at $900^{\circ} \mathrm{C}$ for $3 \mathrm{hr}$, quenched into the oil bath at $200^{\circ} \mathrm{C}$, rolled (ausform), air-cooled to room temperature, and then deep-cooled into liquid nitrogen. Fe-Ni alloy was transformed into martensite in some extent at room temperature, and after deep-cooled at liquid nitrogen temperature, transformed almost completely. In Fe-Ni-C alloy, the martensite was not produced at room temperature, and after deep-cooled about $50 \%$ of austenite was transformed into martensite. The specimens which had not been subjected to rolling were also used for reference, designating as $0 \%$-ausformed or unausformed specimens.

Fig. 1 shows the results of hardness measurements. In the case of $500-\mathrm{g}$ loading, the measurement was made irrespectively of microstructure, while in the case of $50-\mathrm{g}$ loading it was made for martensite and austenite separately. In 500-g loading, the Fe-Ni specimen was scarcely hardened by ausforming, but the Fe-Ni-C specimen was markedly hardened. The hardness of austenite in the $\mathrm{Fe}-\mathrm{Ni}$ specimen was measured before deep-cooling in liquid nitrogen, because after deep-cooling the quantity of austenite was markedly reduced, but in $\mathrm{Fe}-\mathrm{Ni}-\mathrm{C}$ specimen it was

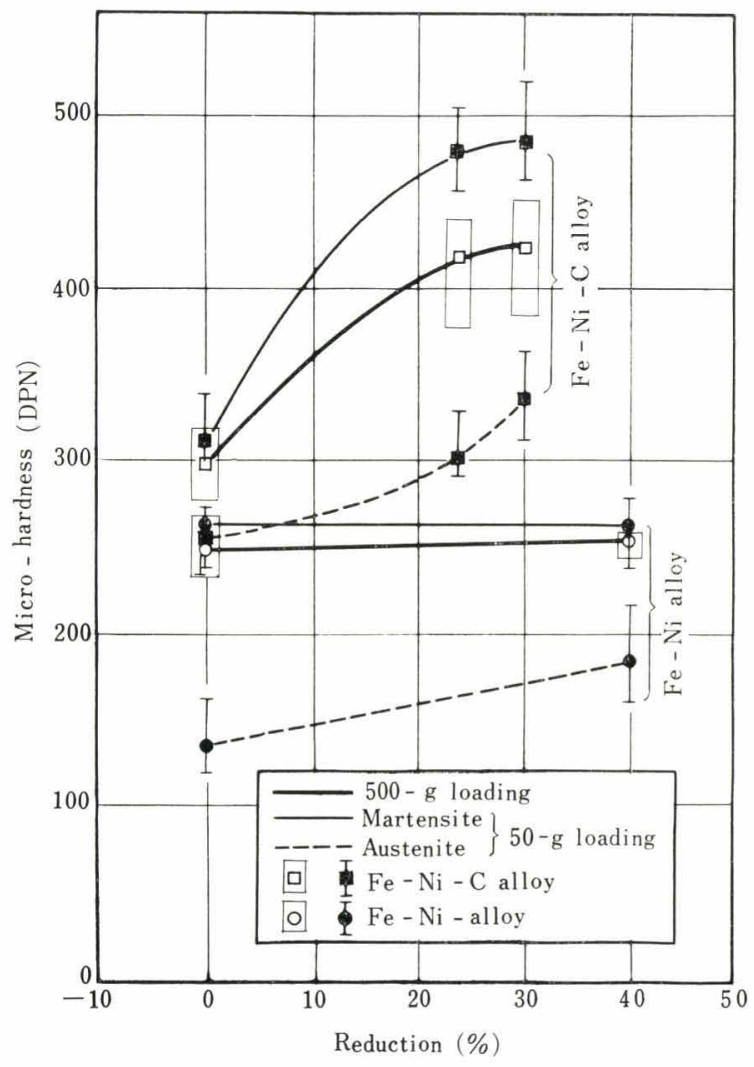

Fig. 1. Micro-hardness of martensite and austenite in ausformed $\mathrm{Fe}-\mathrm{Ni}$ and $\mathrm{Fe}-\mathrm{Ni}-\mathrm{C}$ alloys

* Received September 16, 1966.

** Prof., Dr. Eng.; Department of Metal Science and Technology, Kyoto University, Kyoto. 
measured after deep-cooling. In Fe-Ni specimen, the austenite was hardened by straining, but the increment was smaller than that in $\mathrm{Fe}-\mathrm{Ni}-\mathrm{C}$ specimen. The martensite in $\mathrm{Fe}-\mathrm{Ni}$ specimen was scarcely hardened by ausforming. In $\mathrm{Fe}-\mathrm{Ni}-\mathrm{C}$ specimen, however, not only austenite but also martensite was markedly hardened by ausforming. Moreover, the increment of hardness in martensite by ausforming was larger than hardness increment by strain-hardening in austenite which was parent phase of the martensite. The effect of ausforming was clearly found in Fe-Ni-C alloy but not in $\mathrm{Fe}-\mathrm{Ni}$ alloy. It may, therefore, be considered that some amount of carbon content is essential for strengthening of steel by ausforming.

Justusson, et al. ${ }^{8)}$ have shown that the increment of yield strength of steel by ausforming does not depend on carbon content for a series of steels containing more than $0.3 \% \mathrm{C}$. These results can be explained that an excessive amount of carbon is not effective on strengthening of steel by ausforming, although some amount of carbon is required to increase strength by segregating to dislocations and pinning them. A small amount of carbon may be sufficient to saturate and pin dislocations, depending upon dislocation density which is high in ausformed martensite as will be described later.

Photo 1 shows optical micrographs of $0 \%$ - and 30\%-ausformed Fe-Ni-C specimens after deep-cooling. Both of them had a lightening or zigzag shaped martensite plate. The structure of $30 \%$-ausformed specimen was, however, finer than that of the $0 \%$-ausformed, and the martensite plates were small, warped, bent and kinked, while those in the $0 \%$-ausformed were large and straight. These facts are in agreement with those reported by several researchers. ${ }^{8)-14}$ Such a structure in ausformed specimen may be produced due to the interaction of martensite plates with slip bands and deformation bands (in such locations having high density of dislocations or discontinuities of crystal) existing in deformed austenite during growth of martensite plates.

Photo 2 shows a transmission electron micrograph of martensite and retained austenite in $0 \%$-ausformed Fe-Ni-C alloy. The martensite was typically twinned and had $\{259\}_{\gamma}$ habit plane. Fine parallel bands (transformation twins) ran through the whole martensite plate, and from the shape of these bands at the ends (interface between martensite and austenite) they might be plate-like. There were some lines and dark dotted images between the bands. They are explained as contour fringes and fine precipitates of carbide on twin faults, respectively. The micrograph was very clear and dislocations in the martensite were hardly observed. The structure of austenite was smooth, and there were a few smooth contour fringes and dislocations.

Photo 3 shows an electron micrograph of $30 \%$ ausformed Fe-Ni-C alloy. In martensite, there were several diffused and broad bands. These bands were extinction contour fringes. This fact shows that high stresses of wide range are retained within and around martensite plate in the bulk specimen. When thin foils for transmission electron microscopy were made from the bulk specimen having such retained stresses, it would be bent locally by stresses, and many extinction contour fringes could be observed in the micrograph.

The most important peculiarity of the martensite in

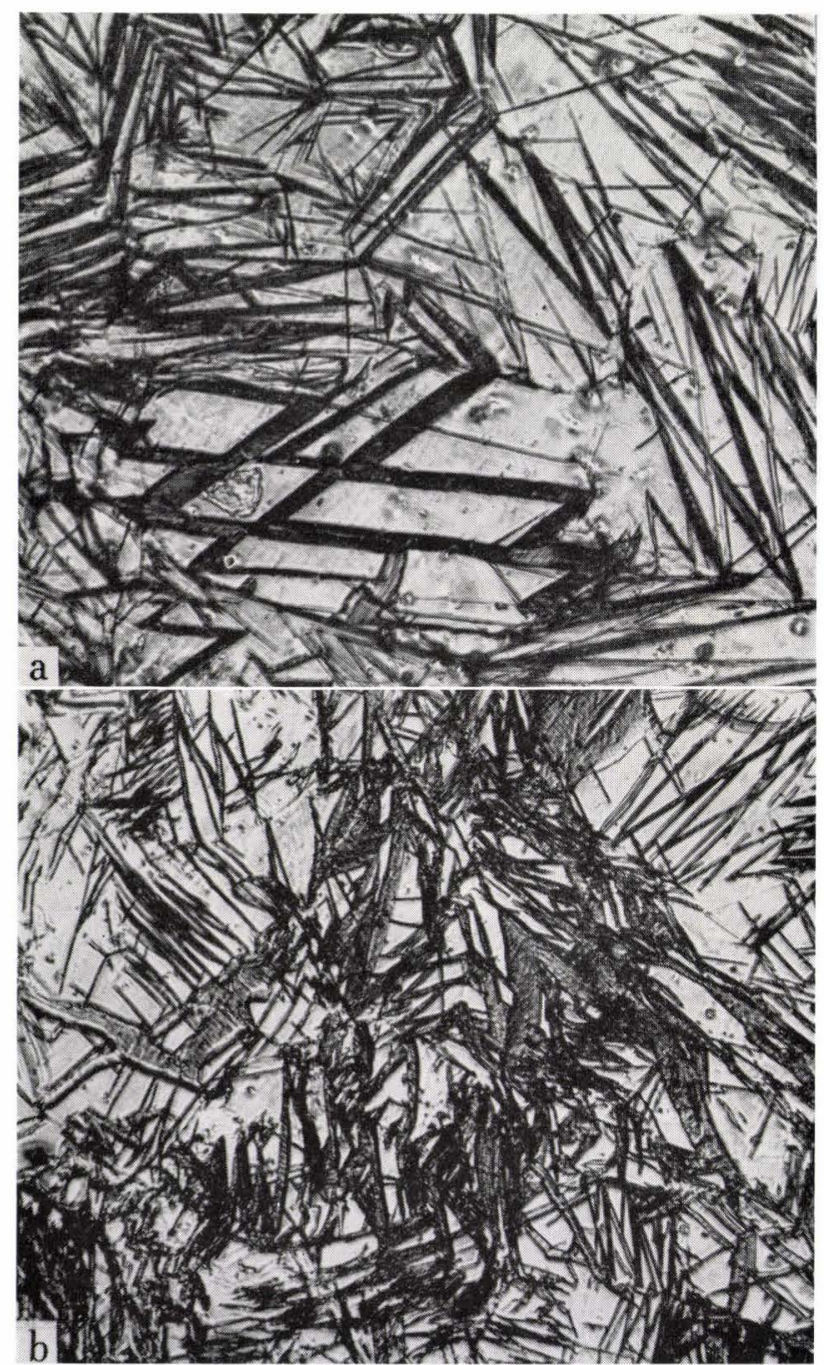

Photo 1. Structures of (a) $0 \%$ - and (b) $30 \%$-ausformed Fe$\mathrm{Ni}-\mathrm{C}$ alloy taken by optical microscope. $(\times 200)$ Etchant: $1 \%$-nital.

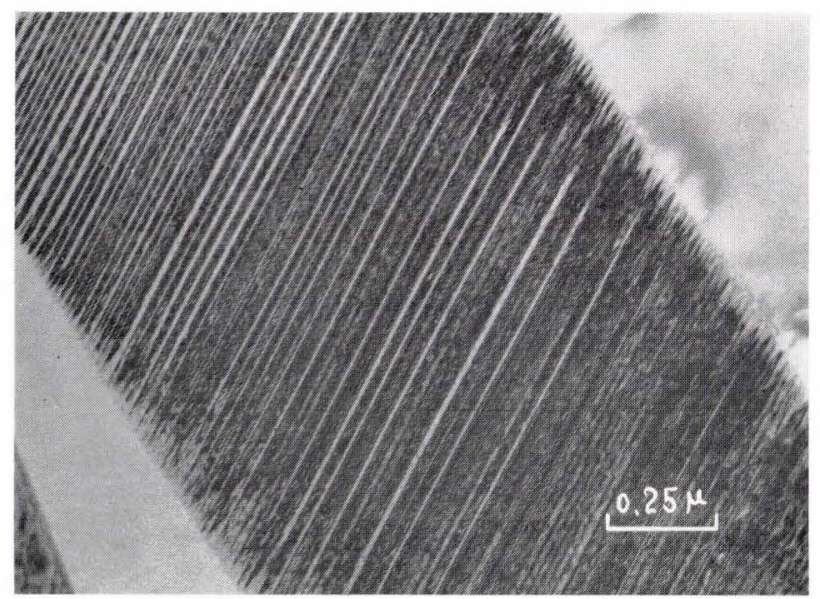

Photo 2. Transmission electron micrograph of $0 \%$-ausformed $\mathrm{Fe}-\mathrm{Ni}-\mathrm{C}$ alloy 


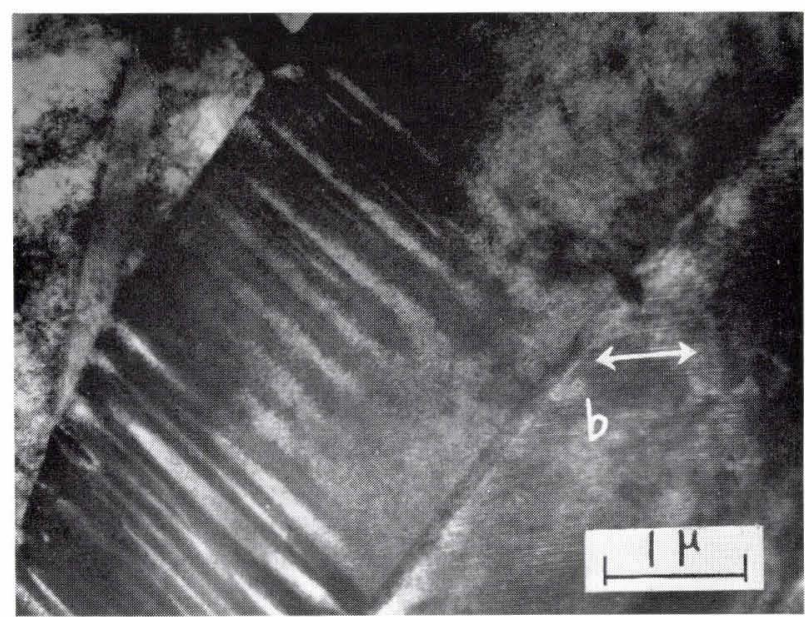

Photo 3. Transmission electron micrograph of $30 \%$-ausformed $\mathrm{Fe}-\mathrm{Ni}-\mathrm{C}$ alloy

ausformed specimen is that the image of the martensite is not clear as observed in Photo 3. Such an image shows the existence of a cloudy distribution of dislocations at which extremely fine particles of carbide may precipitate. Dislocation density was very high in ausformed martensite. Transformation twins were also observed in the ausformed martensite plate (b) in Photo 3 in the same manner as in unausformed martensite. But, usually, it is difficult to observe transformation twins in ausformed martensite because of hindrance of several images of dislocations, fringes and others, while the twinned pattern in electron diffraction is obtained.

In austenite in Photo 3, a dense distribution of dislocations was observed. The austenite was evidently strain-hardened.

Lattice orientation relationship between austenite and martensite was approximately (111) $r / /(011)_{\alpha}$ and $[1 \overline{1} 0]_{r} / /[\overline{\mathrm{I}} 1]_{\alpha}$. Thus, the usual relationship held even in the ausformed state.

\section{Fe-Cr-Ni-C and Fe-Cr-C Alloys (Austenite of Low Stacking Fault Energy ${ }^{3), 15)}$}

$\mathrm{Fe}-14.56 \% \mathrm{Cr}-6.27 \% \mathrm{Ni}-0.38 \% \mathrm{C}$ specimens were prepared in the same method as in the $\mathrm{Fe}-\mathrm{Ni}$ specimens. The specimen was austenitized at $1100^{\circ} \mathrm{C}$ for $3 \mathrm{hr}$, quenched into the oil bath at $200^{\circ} \mathrm{C}$, de- formed by rolling (ausform), subsequently air-cooled to room temperature. Some of specimens were deepcooled in liquid nitrogen, when they were desired to reduce retained austenite.

Fig. 2 shows micro-hardness change (25-g load) of martensite and austenite, separately, with reduction by rolling. In this alloy, strain-hardening of austenite was remarkable because of low stacking fault energy of austenite. The increment of hardness of martensite formed from strain-hardened austenite was not so much at the low reduction, compared with the case of Fe-Ni-C alloy, and less than the strain-hardening of the parent austenite. But, if the reduction increased more than $30 \%$, the increment of hardness in martensite rapidly increased while the rate of strain-hardening in the parent austenite was gradually decreased.

Photo 4 shows the optical microstructures of 10\%ausformed Fe-Cr-Ni-C alloy. Photo $4($ a) is the aircooled state to room temperature. The specimen had a lot of residual austenite in which striations in two directions could be found due to deformation. These

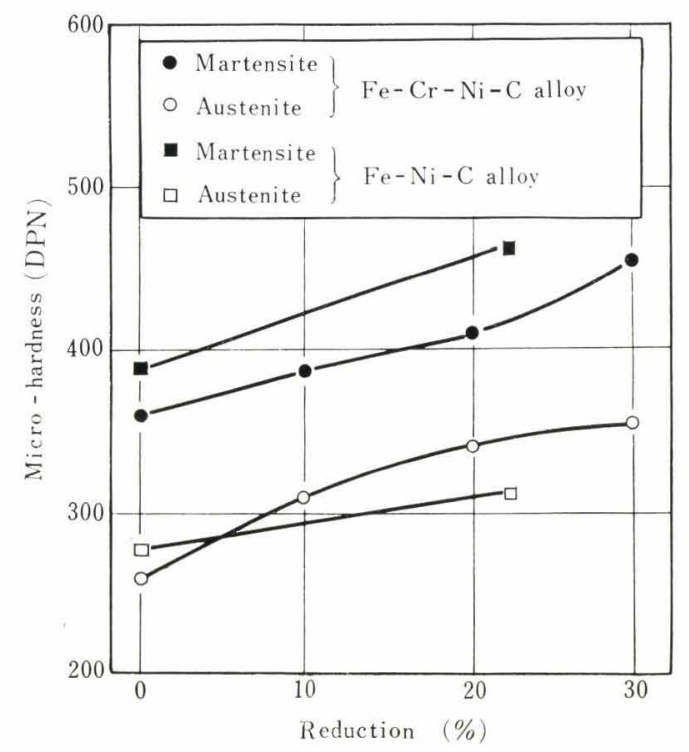

Fig. 2. Micro-hardness of martensite and austenite in ausformed $\mathrm{Fe}-\mathrm{Cr}-\mathrm{Ni}-\mathrm{C}$ alloy, and $\mathrm{Fe}-27.56 \% \mathrm{Ni}-$ $0.44 \% \mathrm{C}$ alloy for reference

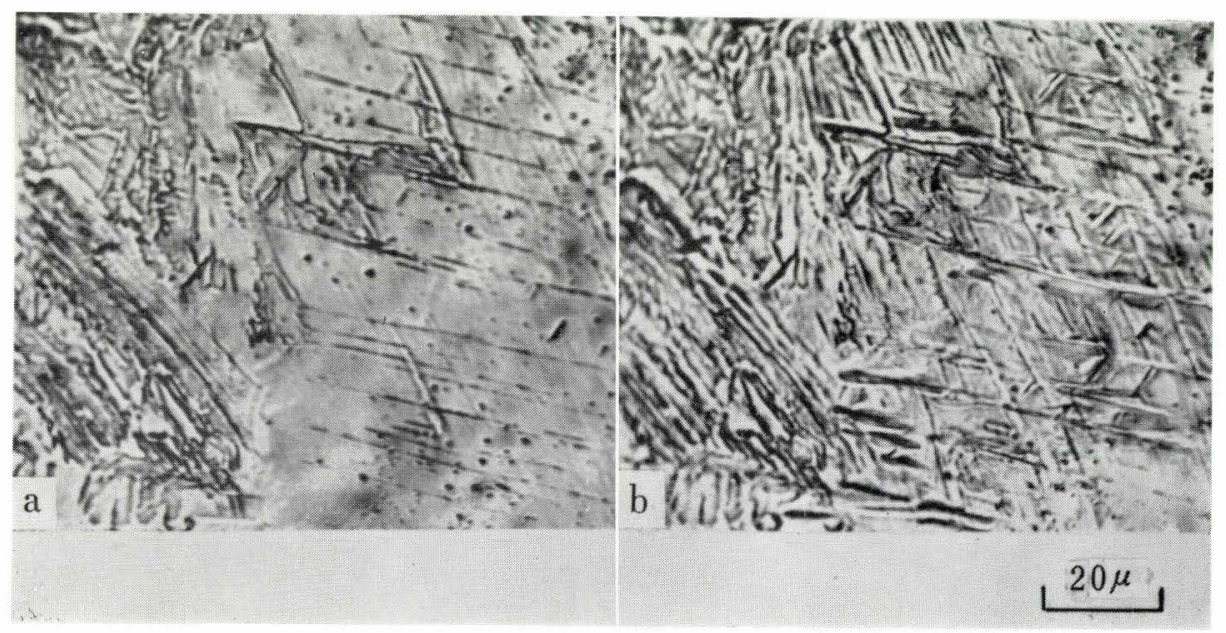

(a) Air-cooled

(b) Sub-zero cooled in liquid nitrogen

Photo 4 .

Optical micrographs of $10 \%$-ausformed $\mathrm{Fe}-\mathrm{Cr}-\mathrm{Ni}-\mathrm{C}$ alloy.

Etchant : HCl-picral. 
striations may be $\varepsilon$-phase. Photo $4(\mathrm{~b})$ is identical view after deep-cooled in liquid nitrogen in the same specimen as in Photo 4(a). It can be found that martensite forms along and/or from the striations.

Photo 5 shows a transmission electron micrograph of $0 \%$-ausformed $\mathrm{Fe}$-Cr-Ni-C alloys. This structure was a typical lath martensite having lots of dislocations but no transformation twins.

Photo 6 shows an electron micrograph of $10 \%$ ausformed $\mathrm{Fe}-\mathrm{Cr}-\mathrm{Ni}-\mathrm{C}$ alloy. In austenite, there were striations which were $\varepsilon$-phase, and in both austenite and martensite dislocation density was high. Orientation relationship among austenite, $\varepsilon$-phase and martensite was $(111)_{\gamma} / /(0001)_{\varepsilon} / /(011)_{\alpha},[10 \overline{1}]_{\gamma}$

$[11 \overline{2} 0]_{\varepsilon} / /[1 \overline{1} 1]_{\alpha}$ determined by electron diffraction pattern in selected area. In the other micrographs, some striations of the trace of $\{011\}_{\alpha}$ planes in martensite were sometimes observed. These striations

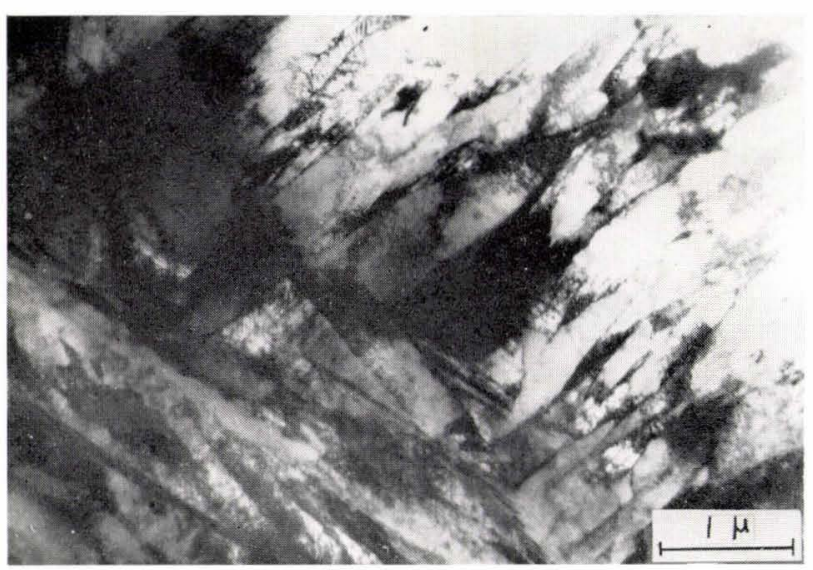

Photo 5. Transmission electron micrograph of unausformed $\mathrm{Fe}-\mathrm{Cr}-\mathrm{Ni}-\mathrm{C}$ alloy

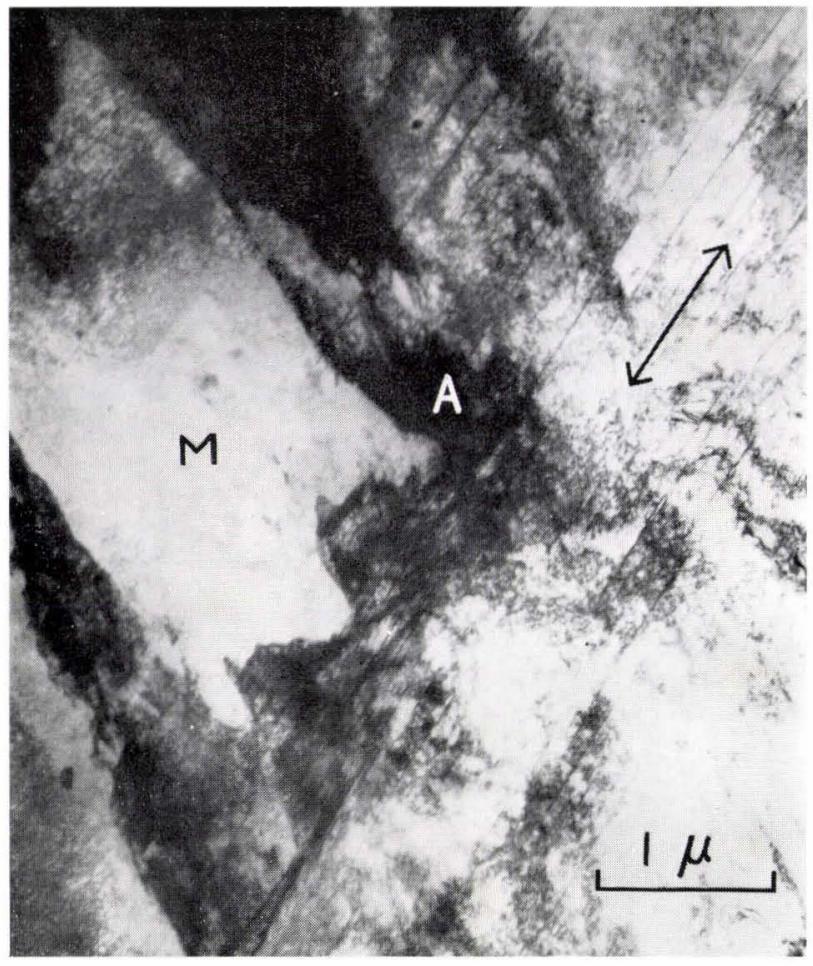

Photo 6. Transmission electron micrograph of 10\%-ausformed $\mathrm{Fe}-\mathrm{Cr}-\mathrm{Ni}-\mathrm{C}$ alloy could be traces of $\{111\}_{\gamma}$-twin boundary in austenite produced by deformation.

Photo 7 shows an electron micrograph of $30 \%$ ausformed Fe-Cr-Ni-C alloy. The shape of martensite plate was very irregular and dislocation density in the martensite was very high. In the other micrographs, transformation twins were sometimes observed.

Photo 8 shows electron micrographs and diffraction patterns of unausformed martensite. The direction of incident beam was $[\overline{3} 11]_{\alpha}$. By tilting the specimen, when the spot from $(112)_{\alpha}$ plane appeared alone in the pattern as shown in Photo $8\left(a^{\prime}\right)$, in the micrograph (a) dislocations were hardly observed and appeared only contour fringes. When the spot from (121) $\alpha$ plane appeared alone as shown in the pattern $\left(b^{\prime}\right)$, in the micrograph (b) lots of dislocations were observed. It showed that there were no dislocations except the dislocations having Burgers vector of $\frac{1}{2}[11 \overline{1}]_{\alpha}$. After all, it was found in unausformed martensite that the

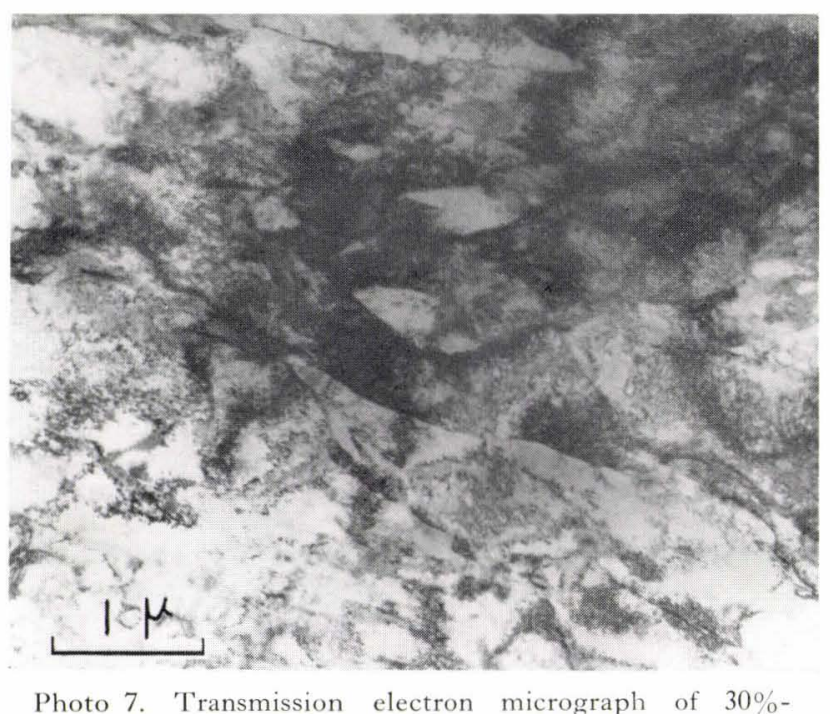
ausformed $\mathrm{Fe}-\mathrm{Cr}-\mathrm{Ni}-\mathrm{C}$ alloy
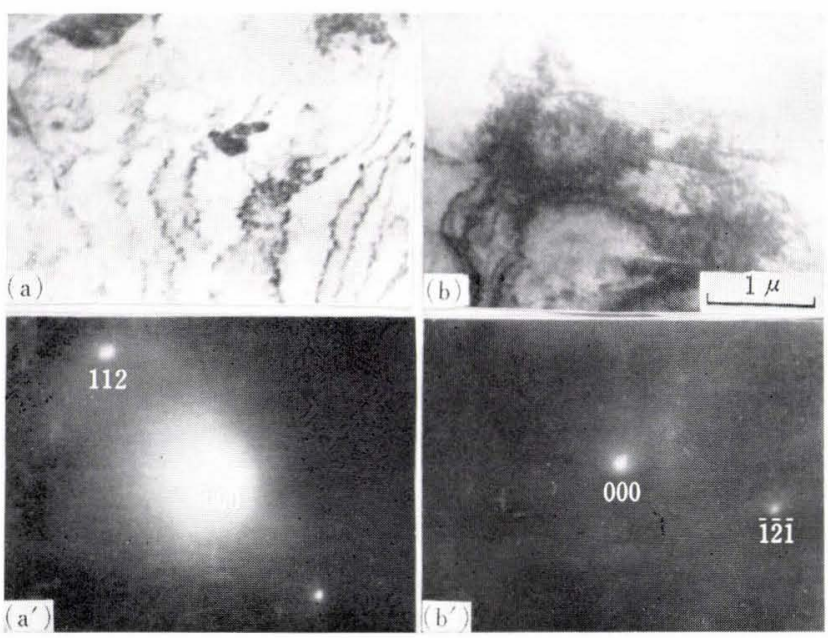

Photo 8. (a) and (b) are transmission electron micrographs, and $\left(a^{\prime}\right)$ and $\left(b^{\prime}\right)$ are electron diffraction patterns in unausformed martensite (Fe-Cr-Ni-C). The dislocations are seen in (b), but not in (a) in which the specimen was tilted from (b). 

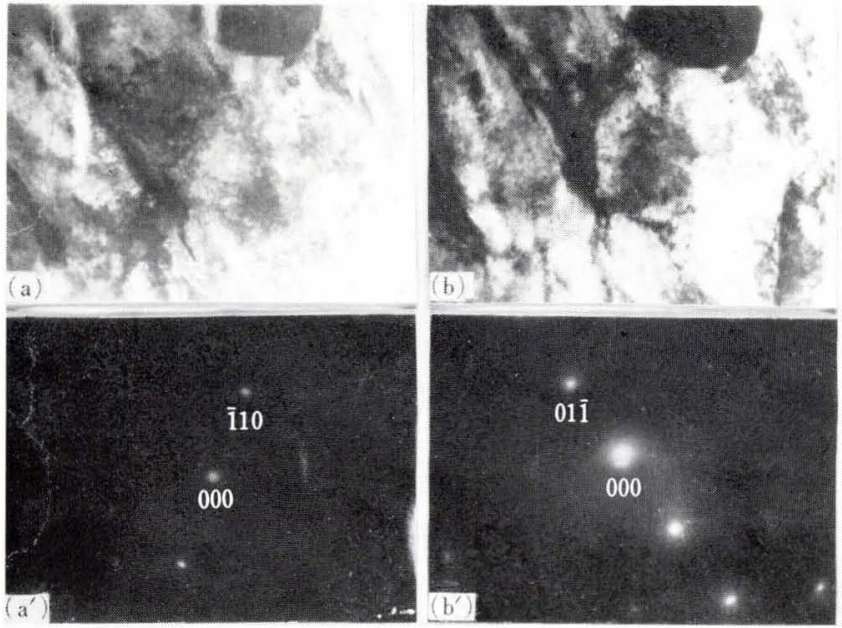

dislocations having only one kind of Burgers vector, $\frac{1}{2}[11 \overline{1}]_{\alpha}$ existed. They would be produced by second shear during martensitic transformation.

Photo 9 shows electron micrographs and diffraction patterns of $30 \%$-ausformed martensite. The direction of incident beam was $[111]_{\alpha}$. By tilting the specimen, the micrographs from simple reflection of $(\overline{110})_{\alpha}$, $(01 \overline{1})_{a}$ and $(\overline{1} 01)_{\alpha}$ were taken, respectively. In all of micrographs lots of dislocations were observed. After all, in ausformed martensite the dislocations had various Burgers vectors of $\frac{1}{2}<111>\alpha^{*}$.

\section{Discussion on Strengthening Mechanism of Steel by Ausforming}

Some amount of carbon content which is sufficient to segregate to dislocations, then pin and multiply them, is essential for strengthening of steel by ausforming. Some amount of carbon could segregate to dislocations in deformed austenite having high stacking fault energy as Fe-Ni-C. Because the rate of strain-hardening of $\mathrm{Fe}-\mathrm{Ni}-\mathrm{C}$ austenite was relatively high compared with that of $\mathrm{Fe}-\mathrm{Ni}$ austenite due to multiplication of dislocations caused by carbon segregations. In Fe-Cr-Ni-C alloy, the austenite has low stacking fault energy and the dislocations spread in some extent, and hence the rate of strain-hardening of austenite is high. In this case, the interaction between the stacking faults and carbon atoms could be relatively weak, if there were no carbide forming elements. ${ }^{16)}$ Carbon atoms would segregate to dislocations after transformation to martensite. According to Winchell et al., ${ }^{17}$ ) the martensite even in unausformed specimen can be age-hardened at room temperature.

It is very interesting that twinned martensite is produced from austenite having high stacking fault energy and untwinned martensite produced from austenite having low stacking fault energy. In twinned martensite (Fe-Ni-C), dislocations were hardly observed in unausformed, but ausformed martensite had both transformation twins and lots of dislocations. In Fe-Cr-Ni-C martensite having no transformation twins, the unausformed martensite had the disloca-

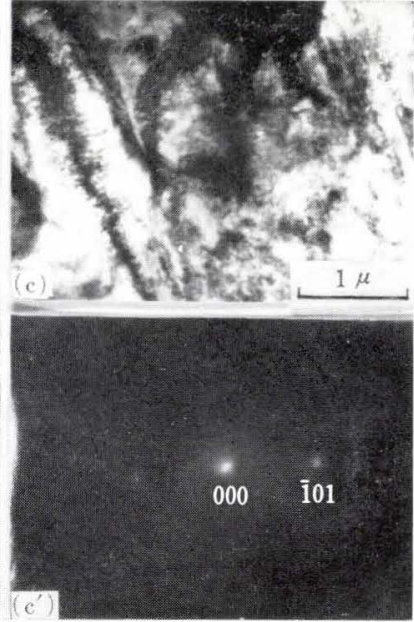

Photo 9.

Transmission electron micrographs and diffraction patterns of $30 \%$-ausformed martensite (Fe-Cr-Ni-C). Dislocations are seen in the three diffracted conditions.

tions having a definite kind of Burgers vector, but the $30 \%$-ausformed martensite had the dislocations having various kinds of Burgers vectors and dislocation density was very high. The large number of dislocations should, therefore, be inherited by martensite from the deformed austenite.

The orientation relationship between austenite and martensite showed $(111)_{\gamma} / /(011)_{\alpha},[1 \overline{1} 0]_{\gamma} / /[\overline{111}]_{\alpha}$. So, dislocations having Burgers vector of $\frac{1}{2}[1 \overline{1} 0]_{\gamma}$ on (111) r plane in austenite could be easily inherited by martensite. But the other $\{111\}_{\gamma}$ planes of austenite tilt in a few degrees to correspond $\{110\}_{\alpha}$ planes of martensite. If dislocations on $\{111\}_{\gamma}$ except (111) r were pinned by carbon segregations, some of them could be inherited by martensite, and some of them could go away during growth of martensite plate. In another case, the growth of martensite plate could be stopped by the regions having high density of dislocations or discontinuities of crystal, i.e. slip bands, deformation bands or grain boundaries. Also, it should be considered that transformation dislocations lying on martensite-austenite interface could interact with the dislocations in austenite. At the present, such interactions are very difficult problem to explain. After all, it could be considered that relatively simple dislocations in austenite were inherited by martensite, and complicatedly interacted or tangled dislocations were not inherited. That is, the dislocations in austenite are screened by austenite-martensite interface and relatively simple dislocations are inherited by martensite. This is very important to explain not only strengthening but also ductility of ausformed steel in addition to refining martensite plate.

In Fe-Ni-C alloy, the rate of hardness increase of martensite was higher than that of strain-hardening of parent austenite with the degree of deformation by ausforming. This would be duplex effect of transformation twins and the rapid increase of dislocation density.

In Fe-Cr-Ni-C alloy, the austenite has low stacking fault energy. Dislocations spread in some extent, i.e. stacking faults, $\varepsilon$-phases and twins could be formed in austenite by deformation. Especially, e-phase is im-

* From the experiment of Photo 9, it could not be discussed about Burgers vector of $\frac{1}{2}[111]_{\alpha}$. 
portant in this discussion, because $\varepsilon$-phase can become an intermediate phase to transformation from austenite to martensite. Not only $\varepsilon$-phase itself can directly and easily be transformed into martensite, but also can induce and accelerate the transformation from austenite to martensite. The $\varepsilon$-phase is an accumulation of stacking faults in layer by layer on a $\{111\}_{r}$ plane and is one kind of imperfections of austenite by deformation. However, since the $\varepsilon$-phase itself transforms into usual martensite, the $\varepsilon$-phase is not inherited by martensite as a kind of imperfections. Of course, some of dislocations could be inherited even in such a case, but the amount of inherited imperfections could be lower than the case of Fe-Ni-C alloy. This could be the reason why the rate of hardness increase of ausformed Fe-Cr-Ni-C martensite was low compared with that of $\mathrm{Fe}-\mathrm{Ni}-\mathrm{C}$ martensite, while strain-hardening of parent austenite of $\mathrm{Fe}-\mathrm{Cr}-\mathrm{Ni}-\mathrm{C}$ alloy was high with the degree of deformation.

However, if the degree of deformation of austenite becomes larger and dislocation density in austenite is increased, the dislocations are difficult to spread, due to repulsive force acting each other. Therefore, it becomes difficult to form stacking faults, $\varepsilon$-phases and/or twins in heavily deformed austenite even which has low stacking fault energy. In such a condition, the dislocations exist in nearly perfect state in the austenite, and in the martensite transformation twins can sometimes observed, as also shown by Kelly et al. ${ }^{18)}$ That is, the austenite even which has low stacking fault energy, behaves as if the stacking fault energy became higher. In Fe-Cr-Ni-C alloy ausformed more than $30 \%$-reduction, the rate of hardness increase of martensite increased and showed similar behaviour as that of Fe-Ni-C alloy with increasing degree of deformation of austenite, while the rate of strain-hardening of parent austenite was lowered.

\section{Tempering Behaviour of Ausformed Mar- tensite}

\section{Tempering of Ausformed Fe-Ni-C Martensite Having Transformation Twins $^{2), 4)}$}

An $\mathrm{Fe}-27.56 \% \mathrm{Ni}-0.44 \% \mathrm{C}$ alloy was prepared by the same procedure as the formerly mentioned alloys. The specimens were ausformed at $200^{\circ} \mathrm{C}$ by $0 \%$ - and $22 \%$-reduction and deep-cooled to liquid nitrogen temperature, and then tempered for $1 \mathrm{hr}$ up to $500^{\circ} \mathrm{C}$ at an interval of $50^{\circ} \mathrm{C}$.

Micro-hardness (50-g loading) of martensite and austenite are shown in Fig. 3. Hardness of ausformed martensite was obviously higher than that of unausformed at room temperature, and eventually at $500^{\circ} \mathrm{C}$ reached the almost same hardness as that of austenite, because the martensite might transform to austenite at $500^{\circ} \mathrm{C}$. The ausformed martensite showed higher hardness than the unausformed throughout the range of tempering temperatures, and maintained high hardness level up to higher temperature than the unausformed. It is one of typical features of ausforming of steel that resistance to hard-

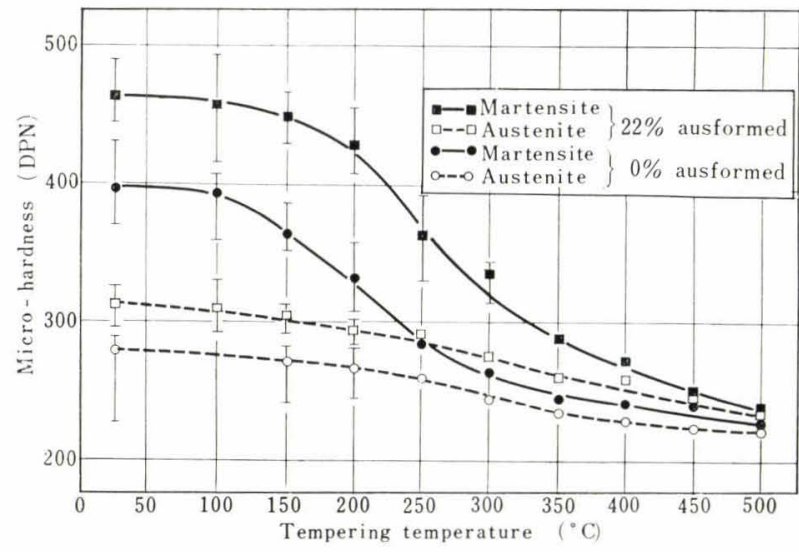

Fig. 3. Micro-hardness of tempered martensite and austenite in unausformed and 22\%-ausformed Fe-Ni-C alloy

ness decrease by tempering is increased. Hardness of austenite in ausformed specimen was slightly decreased by tempering, but was higher than in unausformed specimen throughout the range of tempering temperatures due to strain-hardening.

By observation of optical microscopy, the tempered martensite in ausformed specimen was less etched with nital than that in the unausformed throughout the range of tempering temperatures if the specimens were tempered at the same temperature.

By observation of electron microscopy, in ausformed and $200^{\circ} \mathrm{C}$-tempered martensite, plate-like $\varepsilon$-carbide precipitates were observed on boundaries of transformation twins, and dislocation density was high. Photo 10 (a) shows a structure of unausformed and $300^{\circ} \mathrm{C}$-tempered specimen. There were transformation twins and plate-like carbide along boundaries of transformation twins in the tempered martensite plate. Several dislocations were locally observed, but their density was not so high. In the diffraction pattern, a twin relation was recognized for matrix and several spot for cementite were superposed. Photo 10 (b) shows a structure of $22 \%$-ausformed and $300^{\circ} \mathrm{C}$ tempered martensite. Transformation twins and plate-like carbide particles along them were also observed. Moreover, dense and cloudy dislocations were found in a dotted-like state. A few white regions were observed where dislocations might be diminished as a result of tempering. In the diffraction pattern, there were some spots due to cementite in addition to the spots for tempered martensite matrix which held a twin relation.

Photo 11 shows an electron micrograph of unausformed and $400^{\circ} \mathrm{C}$-tempered specimen. Dark contrasts of parallelogram-shape were clearly observed. They were analysed from diffraction pattern as cementite precipitated on $\{112\}_{\alpha}$ plane which was twinning plane. However, the twin pattern of matrix was hardly observed and the trace of boundaries of transformation twins were slightly observed in the micrograph deviated from the trace of $\{112\} \alpha$ plane, and spacing of twins became wide. That is, transformation twins were gradually migrating and vanish- 


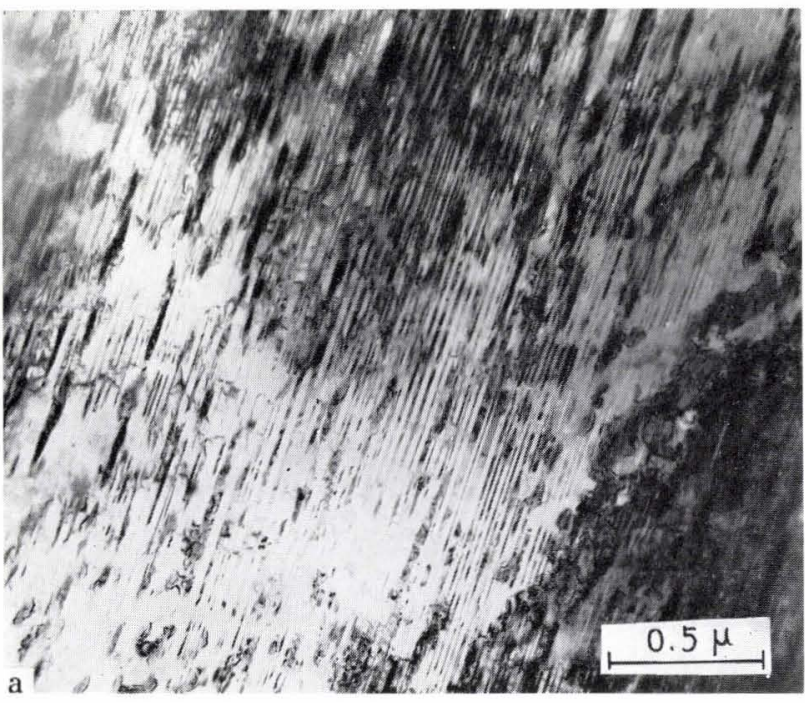

(a) Unausformed

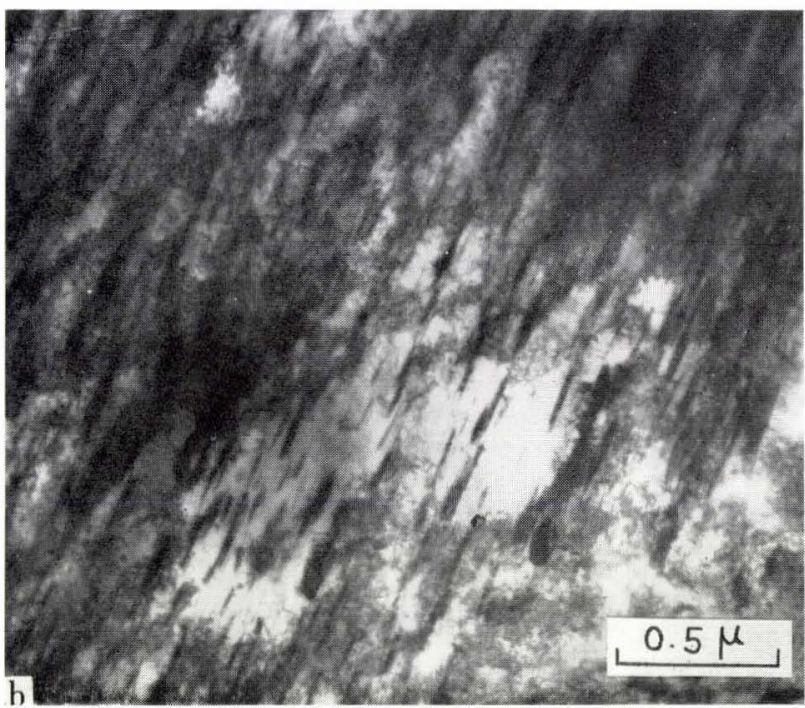

(b) $22 \%$-ausformed

Photo 10. Transmission electron micrographs of $300^{\circ} \mathrm{C}$ tempered martensite ( $\mathrm{Fe}-\mathrm{Ni}-\mathrm{C})$

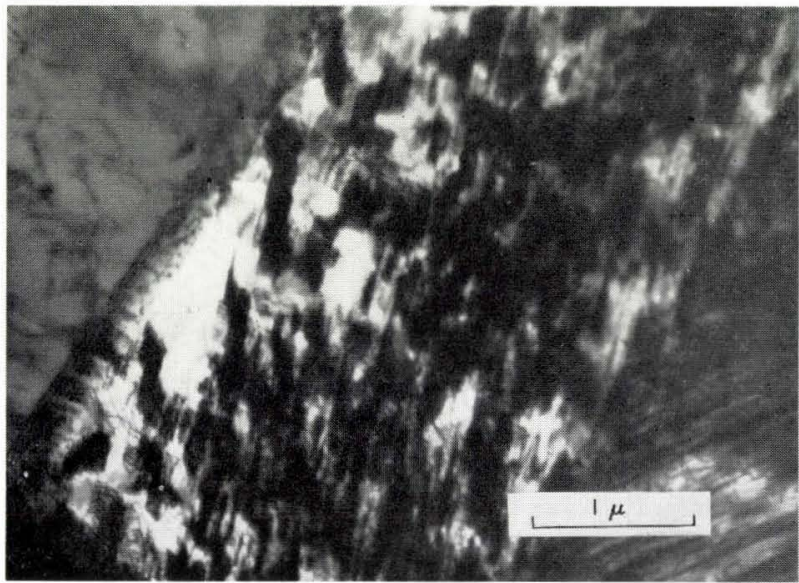

Photo 11. Transmission electron micrograph of $400^{\circ} \mathrm{C}$ tempered unausformed martensite ( $\mathrm{Fe}-\mathrm{Ni}-\mathrm{C}$ ) ing at this temperature. Also, dislocation density was much lowered.

Photo 12 shows an electron micrograph of ausformed and $400^{\circ} \mathrm{G}$-tempered specimen. Parallelogram-shaped contrast of plate-like cementite on $\{112\}_{\alpha}$ plane were observed in tempered martensite. The $\{112\}$ a plane was formerly the boundaries of transformation twins. But, the transformation twins were hardly observed in this state. Distribution of dislocations was clearly observed in lines, not in a dotted-like state. The dislocations joined with the carbide plate. The dislocation density was obviously higher than that in the unausformed. It seems that precipitated carbides hardly grow at the dislocations but grow on twin boundaries during tempering.

The parallelogram-shaped cementite precipitates along $\{112\}_{\alpha}$ plane as observed in Photo 12 are projected images to the photograph plane. Fig. 4 shows a three dimensional model of the cementite plate. This model was established from analysis of diffraction pattern and the direction of twinning shear in the micrograph. From the model, the real width of the cemetite plate in $22 \%$-ausformed specimen, shown in Photo 12 was estimated to be $500-2000 \AA$, and in the unausformed specimen, shown in Photo 11 , to be $500-4000 \AA$, which was larger than that of the ausformed. Concerning number of cementite plates, both specimens were almost same. It could, therefore, be considered that in ausformed specimen the amount of cementite on twin boundery was less than that in the unausformed.

Besides, even in ausformed specimen, the orientation relationship between cementite $(\theta)$ and matrix $(\alpha)$ during tempering of martensite was found to be $(211)_{\alpha} / /(001)_{\theta}, \quad[011]_{\alpha} / /[100]_{\theta}, \quad[1 \overline{1} 1]_{\alpha} / /[010]_{\theta}$ within a few degrees. This relationship agrees with

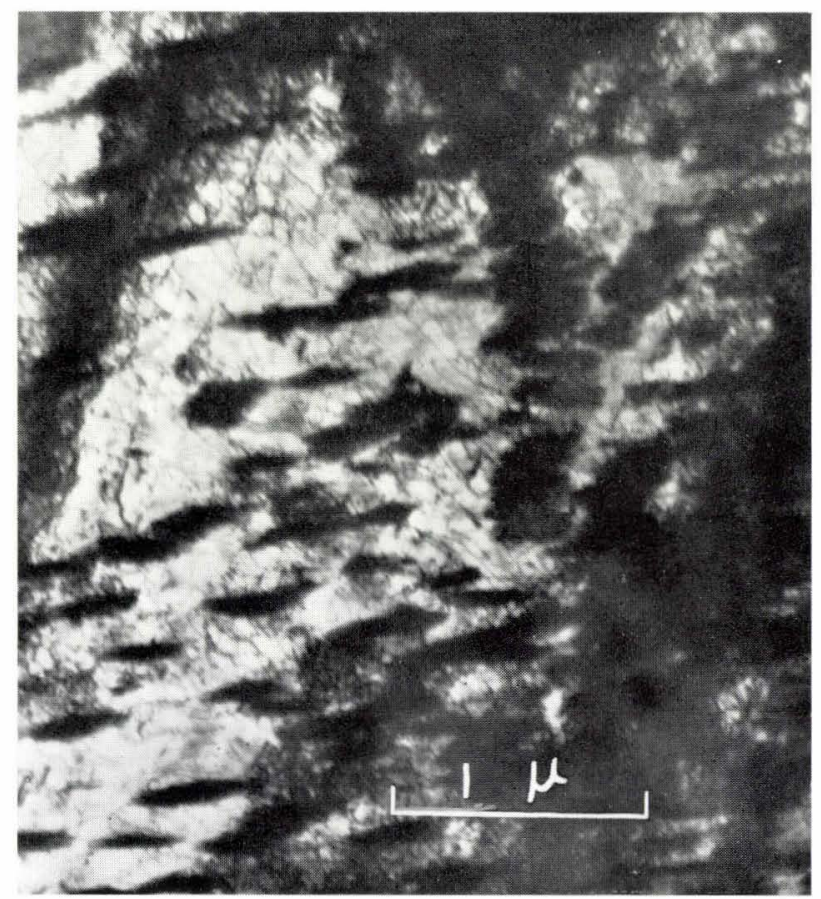

Photo 12. Transmission electron micrograph of $400{ }^{\circ} \mathrm{C}$ tempered 22\%-ausformed martensite ( $\mathrm{Fe}-\mathrm{Ni}$-C) 


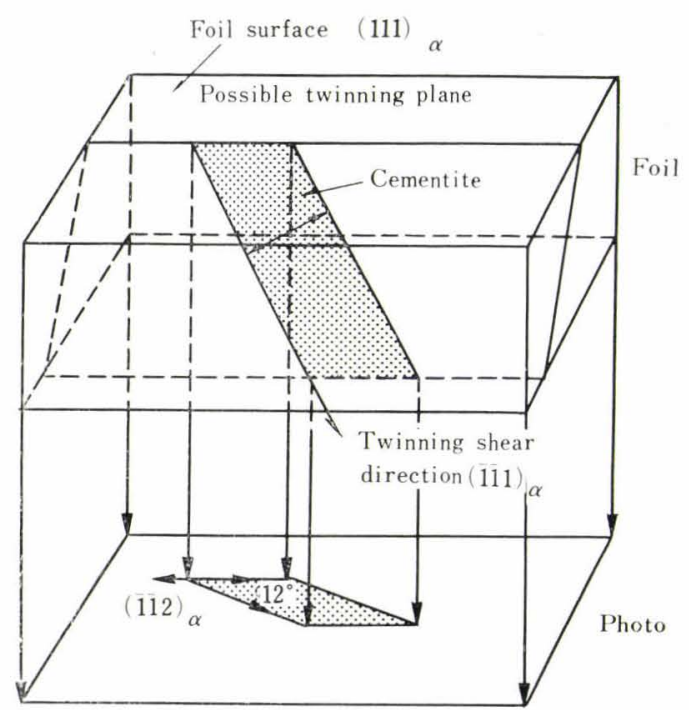

Fig. 4. Three dimensional model of parallelogram-shaped cementite plate on twinning plane, observed in the micrograph of Photo 12

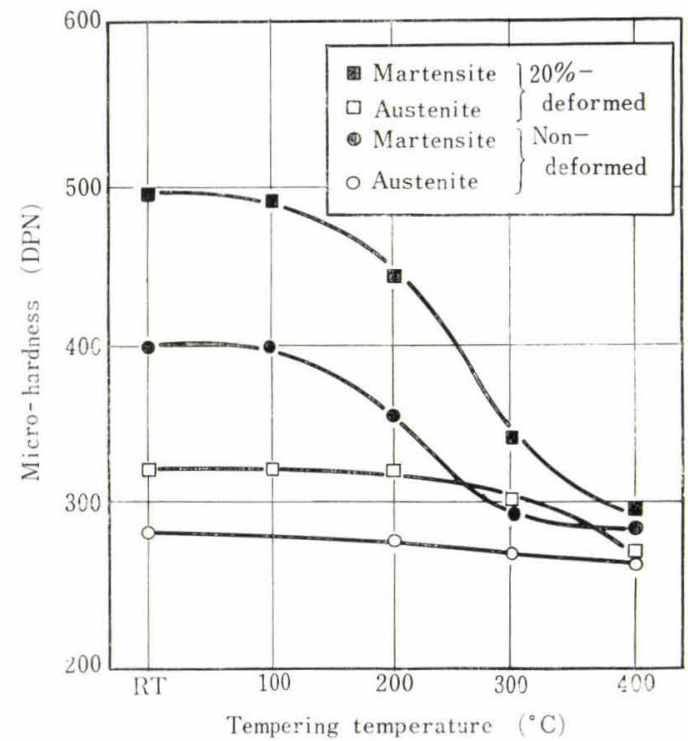

Fig. 5. Micro-hardness of tempered martensite and austenite in unausformed and 30\%-ausformed $\mathrm{Fe}-\mathrm{Cr}$ $\mathrm{Ni}-\mathrm{C}$ alloy, and $\mathrm{Fe}-27.56 \% \mathrm{Ni}-0.44 \% \mathrm{C}$ alloy for reference

the results obtained by Pitsch et al. ${ }^{19)}$ and by Petch $^{201}$ for unausformed specimen.

\section{Tempering of Ausformed Fe-Cr-Ni-C Martensite Hav- ing No Transformation Twins}

The specimens were $\mathrm{Fe}-14.56 \% \mathrm{Cr}-6.27 \% \mathrm{Ni}-$ $0.38 \% \mathrm{C}$. They were the same as former Fe-Cr-Ni-C alloy and were ausformed as the same procedure, and then tempered for $1 \mathrm{hr}$ up to $400^{\circ} \mathrm{C}$.

Fig. 5 shows the micro-hardness change of martensite in ausformed and unausformed specimens with tempering temperature, and also shows that for Fe$\mathrm{Ni}-\mathrm{C}$ alloy for a reference. The similar results were shown as that for Fe-Ni-C martensite, but resistance to hardness decrease by tempering in unausformed and

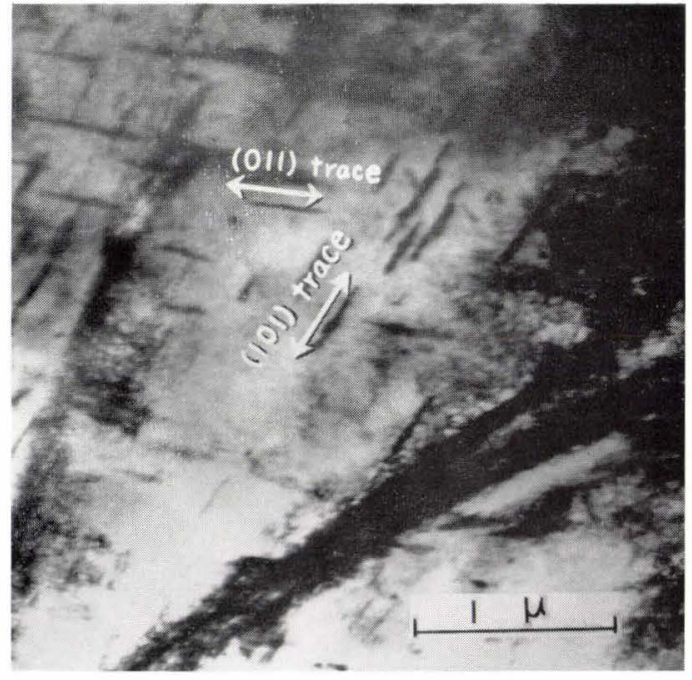

Photo 13. Transmission electron micrograph of $400{ }^{\circ} \mathrm{C}$ tempered unausformed martensites $(\mathrm{Fe}-\mathrm{Cr}-\mathrm{Ni}-\mathrm{C})$

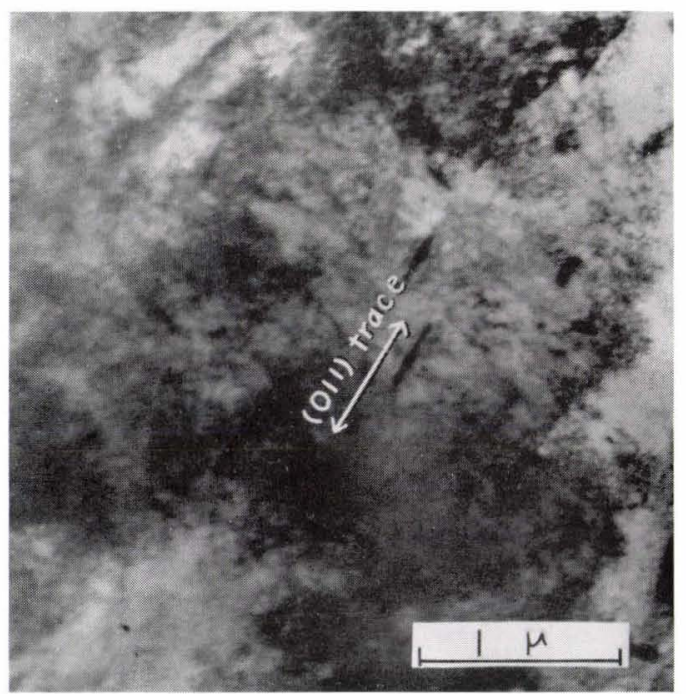

Photo 14. Transmission electron micrograph of $400^{\circ} \mathrm{C}$ tempered $30 \%$-ausformed martensite $(\mathrm{Fe}-\mathrm{Cr}$ $\mathrm{Ni}-\mathrm{C})$

especially in ausformed specimen was higher than for $\mathrm{Fe}-\mathrm{Ni}-\mathrm{C}$ martensite.

Photos 13 and 14 show electron micrographs of $0 \%$ and $30 \%$-ausformed and $400 \mathrm{C}$-tempered martensites, respectively. In these mircographs, plate-like cementites precipitated on $\{110\}_{\alpha}$ plane in two directions as Widmannstätten structure. There were no transformation twins. Even in unausformed specimen (Photo 13), dislocation density was considerably high. In ausformed specimen (Photo 14), dislocation density was much higher than not only in unausformed Fe$\mathrm{Cr}-\mathrm{Ni}-\mathrm{C}$ specimen but also in ausformed $\mathrm{Fe}-\mathrm{Ni}-\mathrm{C}$ specimen tempered at $400^{\circ} \mathrm{C}$. In ausformed $\mathrm{Fe}-\mathrm{Cr}$ $\mathrm{Ni}-\mathrm{C}$ specimen, the amount of cementite was also less than in unausformed specimen.

\section{Discussion on Resistance of Ausformed Martensite to Hardness Decrease by Tempering}

In ausformed and tempered martensites of both Fe-Ni-C and Fe-Cr-Ni-C alloys, dislocation density was higher and the amount of cementite was less than in 
unausformed martensites by tempering at the same temperature.

Since the ausformed martensite has high dislocation density, it has a large number of nucleation sites of carbide at the dislocations. The carbides can also precipitate on the boundaries of transformation twins or $\{110\}_{\alpha}$ planes (habit plane) directly or through dislocations, and the carbides on twin boundaries or habit planes can grow with increasing tempering temperature. The carbides hardly grow at dislocations. In ausformed martensite, carbide precipitation and its growth on twin boundary or habit plane are depressed and delayed during tempering by presence of dense dislocations, because some amount of carbon are kept in dense dislocations. After all, carbide size and spacing are consequently refined and hence carbide precipitates are dispersed closely as long as the dislocations are not eliminated.

The resistance of $\mathrm{Fe}-\mathrm{Cr}-\mathrm{Ni}-\mathrm{C}$ martensite to hardness decrease by tempering was higher than that of Fe-Ni-C martensite. Because diminished temperature of dislocations of the former is higher than that of the latter.

Effect of alloying elements, especially carbide forming elements, Mo, V, etc. will be discussed in next paragraph.

\section{Some Experiments on Ausforming of Tool Steels ${ }^{5)}$}

The effect of ausforming on strength, ductility and hardness of several tool steels containing high carbon and high alloying elements as shown in Table 1 were examined by static bending and hardness tests. Ausforming conditions are shown in Table 2.

Table 1. Chemical compositions of steels used

\begin{tabular}{c|c|c|c|c|c|c|c|c|c|c}
\hline Steel & $\mathrm{C}$ & $\mathrm{Si}$ & $\mathrm{Mn}$ & $\mathrm{P}$ & $\mathrm{S}$ & $\mathrm{Cr}$ & $\mathrm{W}$ & Mo & $\mathrm{V}$ & Co \\
\hline SKD 1 & 2.10 & 0.10 & 0.13 & 0.02 & 0.01 & 13.10 & - & - & - & - \\
\hline SKD 11 & 1.41 & 0.28 & 0.22 & 0.02 & 0.01 & 11.90 & - & 0.82 & 0.27 & - \\
\hline SKH 2 & 0.76 & 0.09 & 0.23 & 0.01 & 0.01 & 4.01 & 17.01 & - & 1.12 & - \\
\hline SKH 4A & 0.80 & 0.13 & 0.22 & 0.01 & 0.01 & 3.90 & 18.10 & - & 1.20 & 10.00 \\
\hline SKH 9 & 0.79 & 0.09 & 0.20 & 0.02 & 0.01 & 4.20 & 6.71 & 4.10 & 1.81 & - \\
\hline
\end{tabular}

Table 2. Experimental conditions of steels used

\begin{tabular}{c|c|c|c|c}
\hline \multirow{2}{*}{ Steel } & \multicolumn{2}{|c|}{ Austenitizing } & \multicolumn{2}{c}{ Tempering } \\
\cline { 2 - 3 } & $\begin{array}{c}\text { Temperature } \\
\left({ }^{\circ} \mathrm{C}\right)\end{array}$ & $\begin{array}{c}\text { Holding time } \\
(\mathrm{min})\end{array}$ & $\begin{array}{c}\text { Temperature } \\
\left({ }^{\circ} \mathrm{C}\right)\end{array}$ & $\begin{array}{c}\text { Number of } \\
\text { tempering } \\
\text { (times) }\end{array}$ \\
\hline SKD 1 & 970 & 20 & 500 & 2 \\
\hline SKD 11 & 1020 & 20 & $100-700$ & 2 \\
\hline SKH 2 & 1270 & 1 & 570 & 3 \\
\hline SKH 4A & 1290 & 1 & 580 & 3 \\
\hline SKH 9 & 1210 & 1 & $100-700$ & 3 \\
\hline
\end{tabular}

Notes: Rolling at $500^{\circ} \mathrm{C}$ (ausforming).

Holding at tempering temperature for $90 \mathrm{~min}$.

In SKD 1-steel containing about $2 \% \mathrm{C}$ and $13 \% \mathrm{Cr}$, the effect of ausforming on strength and ductility was hardly recognized. SKD 11 -steel containing about $1.4 \% \mathrm{C}, 12 \% \mathrm{Cr}$ and some amounts of $\mathrm{Mo}$ and $\mathrm{V}$, increased in strength and in ductility by $50 \%$-ausforming. Especially, ductility was increased into about 1.3 times. In SKH 2-steel, which was $18 \mathrm{~W}$ 4Cr-1V type high speed steel, strength was slightly increased and ductility was considerably increased. In SKH 4A-steel which was 18W-4Gr-1V-10Co type high speed steel, strengthening was hardly observed but ductility was slightly increased. The most remarkable improvement was gained in SKH 9-steel which was a high speed steel containing Mo, W, V and Cr. Hardness of 50\%-ausformed SKH 9-steel was RC 66.5. This was higher by RC 2 than the unausformed. Yield strength in bending test was 300 $\mathrm{kg} / \mathrm{mm}^{2}$. This was higher by $100 \mathrm{~kg} / \mathrm{mm}^{2}$ than the unausformed. Maximum bending stress was 400 $\mathrm{kg} / \mathrm{mm}^{2}$. This was twice value of the unausformed. Deflection was 2.5 times and absorbed energy was $750 \mathrm{~kg}-\mathrm{mm}$, that was, about 7 times as large as that of the unausformed. (see Figs. 6 and 7)

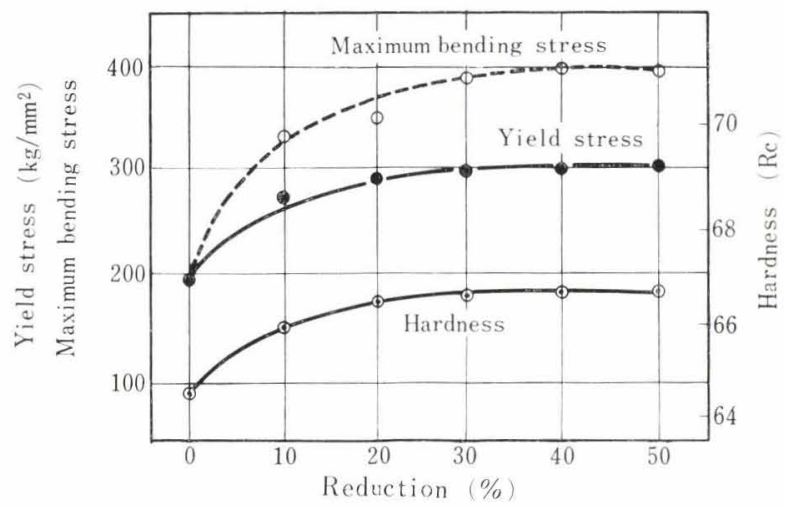

Fig. 6. Effect of reduction in ausforming on yield stress, maximum bending stress and hardness of SKH 9-steel tempered at $570^{\circ} \mathrm{C}$

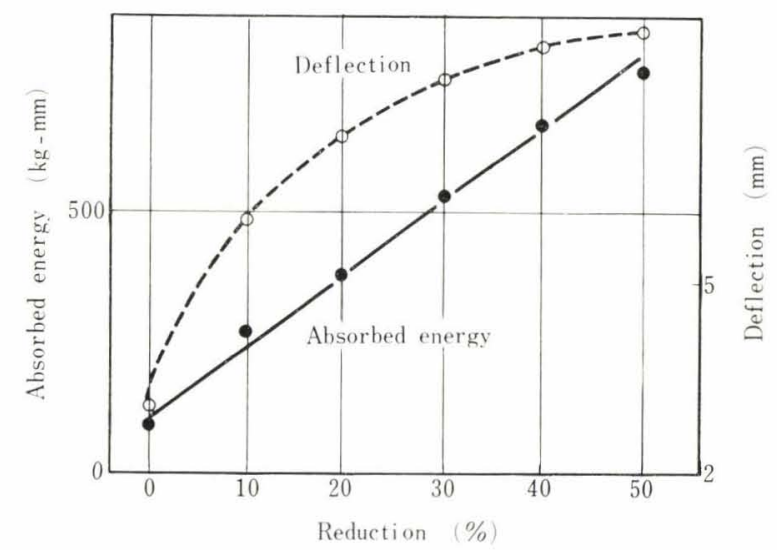

Fig. 7. Effect of reduction in ausforming on absorbed energy and deflection of SKH 9-steel tempered at $570^{\circ} \mathrm{C}$

After all, in high carbon steel having primary carbides, the steel containing only $\mathrm{Cr}$ showed no increment in strength and ductility by ausforming. If the steel contained strong carbide forming elements as Mo, $\mathrm{V}, \mathrm{W}$, etc. which caused secondary hardening by tempering, both strength and ductility were increased. Especially, Mo was most effective. Co in steel lowered the effect of ausforming. 


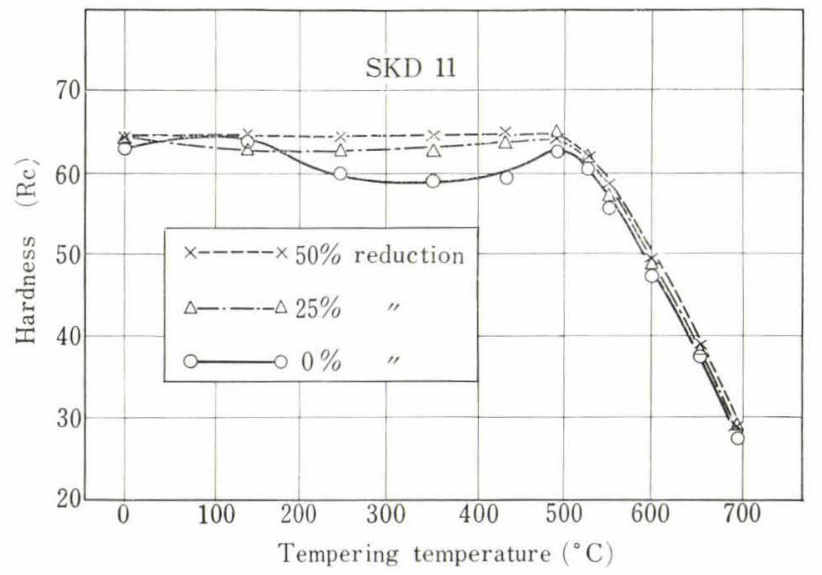

Fig. 8. Hardness of 0,25 and $50 \%$-ausformed SKD 11steel tempered at various temperatures

Fig. 8 shows hardness change of $0 \%-, 25 \%$ - and $50 \%$-ausformed SKD 11 -steels with tempering temperature. While unausformed specimen showed hardness drop in the range of tempering temperature of $300^{\circ}-400^{\circ} \mathrm{C}$, and then showed secondary hardening, such hardness drop in $300^{\circ}-400^{\circ} \mathrm{C}$ became slight with increasing degree of ausforming, and kept high hardness level throughout the whole range of tempering temperatures. Similar results were also obtained in SKH 9-steel. This means that precipitation of alloy carbides which are causes of secondary hardening by tempering in unausformed specimen, has taken place before tempering, probably in metastable austenite state during ausforming. This could be an evidence to support views by McEvily et al. ${ }^{21)}$ and Thomas et al. ${ }^{16)}$ for the steel containing strong carbide forming elements.

\section{Structure and Hardness of Deformed Mar- tensite}

\section{Fe-Ni-C Martensite Having Transformation Twins ${ }^{6), 7)}$}

Richman ${ }^{22}$ ) has reported on deformation modes of Fe-Ni-C martensites having transformation twins at room temperature. According to his results, martensite is deformed by slip when the alloy contains less than 0.05 or $0.1 \% \mathrm{C}$. When the carbon content is $0.1-0.4 \%$, martensite is deformed by both modes of slip and twinning. In case of more than about $0.4 \% \mathrm{C}$, it is deformed by twinning at room temperature. Habit planes of the deformation twins are not only $\{112\}$ but also $\{013\},\{089\}$ and $\{0,1,13\}$ in order of decreasing frequency of occurrence. By the results by Breyer et al., ${ }^{23)}$ deformed martensite of a commercial steel (AISI 4340) has showed strain-hardening, slight strain-softening and a phenomenon of lowering yield point at room temperature with increasing degree of deformation.

The author and his co-workers examined deformation modes and hardness of several Fe-Ni-C and $\mathrm{Fe}-\mathrm{Cr}-\mathrm{Ni}-\mathrm{C}$ martensites, having transformation twins and not, respectively, at several deformation temperatures by means of optical and electron micrographies and micro-hardness tests. The deformation was done by rolling.

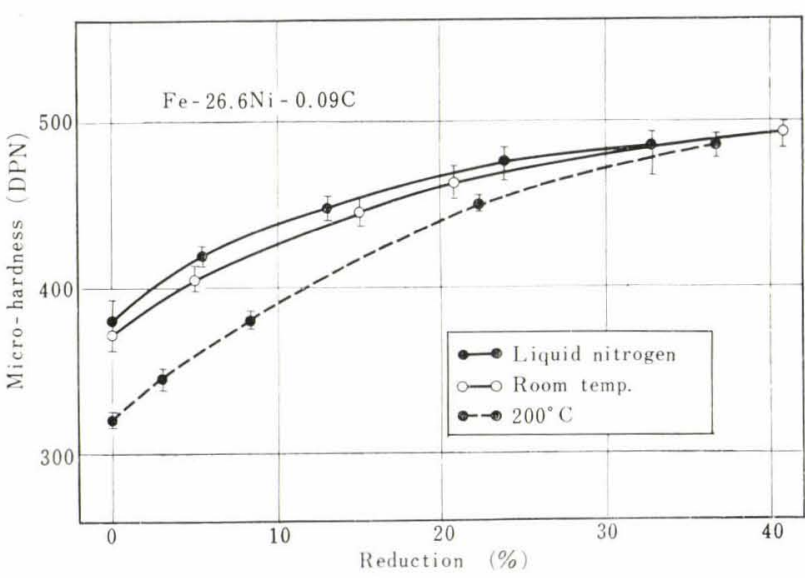

Fig. 9. Hardness change of $\mathrm{Fe}-26.6 \% \mathrm{Ni}-0.09 \% \mathrm{C}$ martensite by rolling at three temperatures

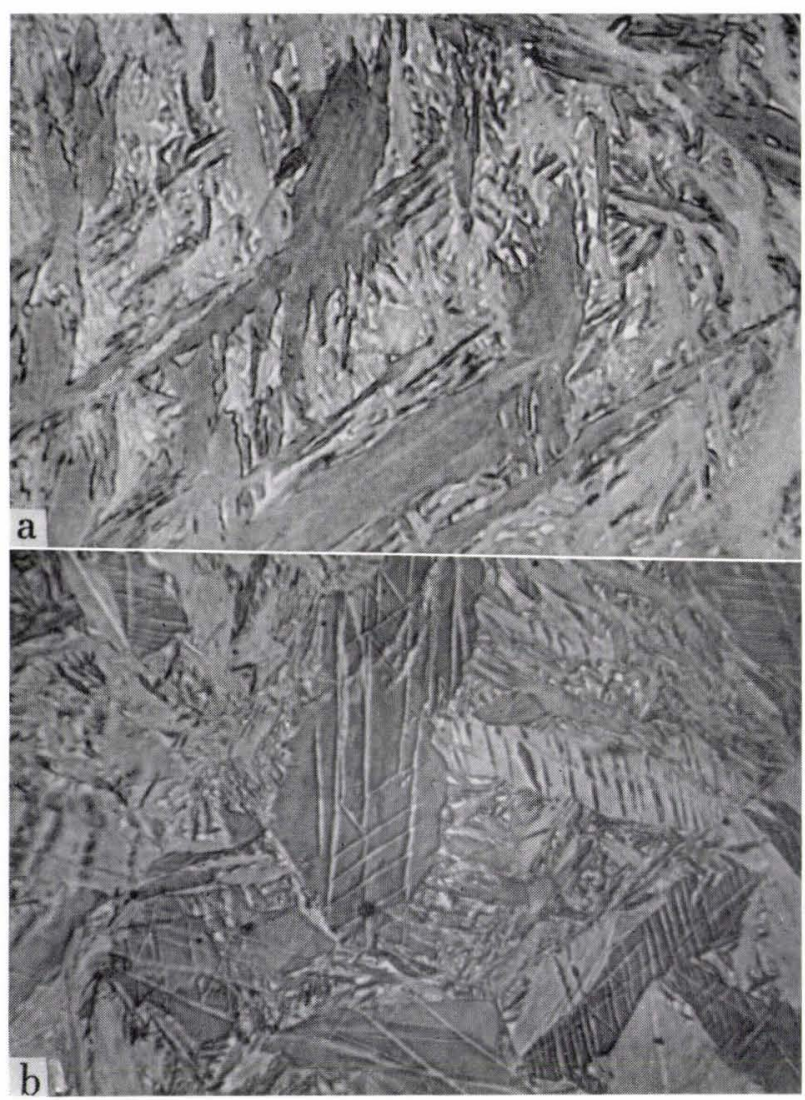

(a) $19 \%$-reduction by rolling at $200^{\circ} \mathrm{C}$

(b) $20 \%$-reduction by rolling at liquid nitrogen temperature

Photo 15. Optical micrographs of $\mathrm{Fe}-24.75 \% \mathrm{Ni}-0.28 \% \mathrm{C}$ martensite $(\times 800)$, Etchant: HCl-picral

Fe-26.6\%Ni-0.09\% C martensite was deformed by slip at either temperatures of $200^{\circ} \mathrm{C}$, room temperature and liquid nitrogen temperature $\left(-196^{\circ} \mathrm{C}\right)$, and hardness with degree of deformation changed in regular style of strain-hardening of metals as shown in Fig. 9. In $\mathrm{Fe}-24.75 \% \mathrm{Ni}-0.2 \% \mathrm{C}$ martensite, it was deformed by slip at $200^{\circ} \mathrm{C}$, by both modes of slip and twinning at room temperature, and by twinning at $-196^{\circ}$ C. Photos 15 (a) and (b) show optical microstructures of (a) 19\%-deformed Fe-24.75\%Ni-0.28\% C martensite at $200^{\circ} \mathrm{C}$ showing deformation by slip and (b) $20 \%$-deformed same martensite at $-196^{\circ} \mathrm{C}$ show- 


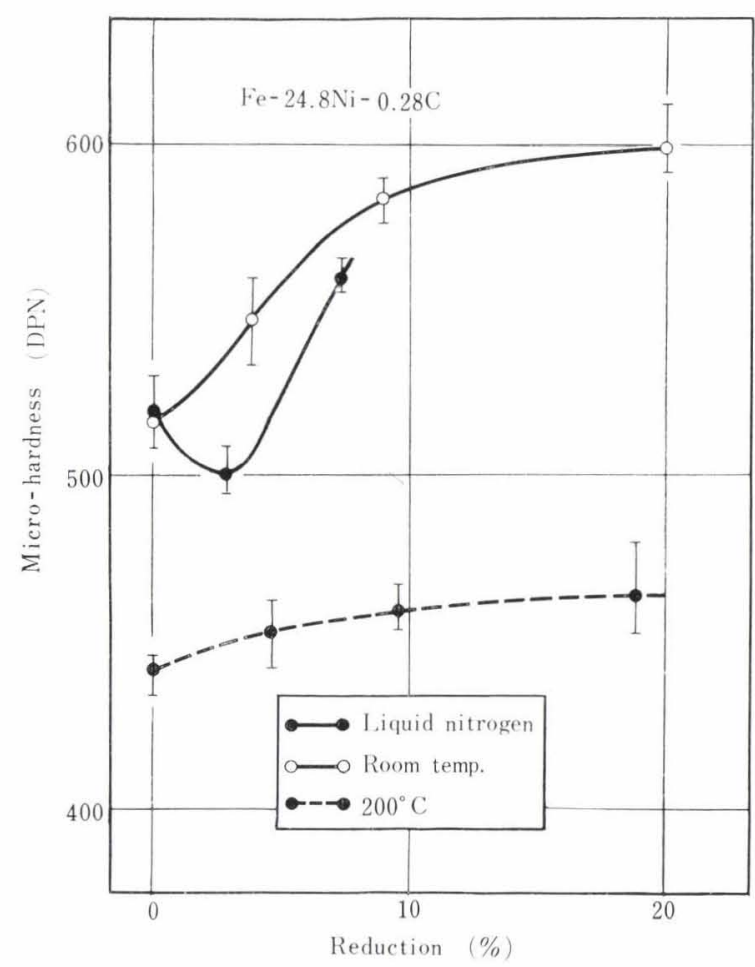

Fig. 10. Hardness change of $\mathrm{Fe}-24.75 \% \mathrm{Ni}-0.28 \% \mathrm{C}$ martensite by rolling at three temperatures

(a)

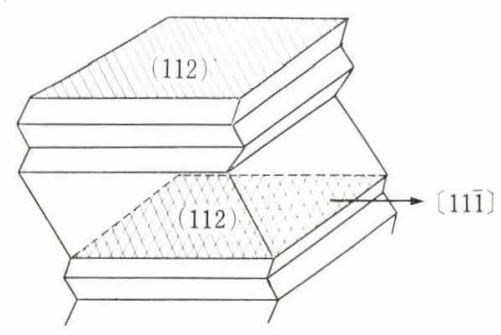

(b)
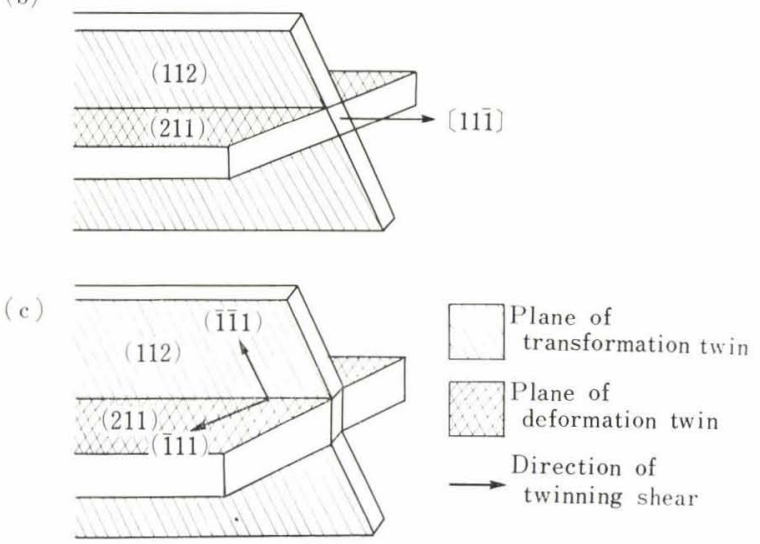

Fig. 11. Three types in relationship between transformation twin and deformation twin

ing deformation by twinning. Fig. 10 shows hardness change of this martensite with reduction of deformation at three temperatures. When the martensite having transformation twins was deformed by twinning, strain-softening took place and the deformed martensite showed a minimum hardness at a few percent of reduction, and then rapidly strain-hardened with increasing degree of deformation after reaching this minimum value. $\mathrm{Fe}-19.4 \% \mathrm{Ni}-0.6 \% \mathrm{C}$ martensite was deformed by slip at $200^{\circ} \mathrm{C}$, and by twinning at room temperature and $-196^{\circ} \mathrm{C}$. In the case of deformation by twinning, the strain-softening was also taken place at a few percent of reduction in the same manner in $\mathrm{Fe}-24.75 \% \mathrm{Ni}-0.28 \% \mathrm{C}$ deformed at -196 ${ }^{\circ}$ C. The deformation mode of twinned martensite depended on carbon content and deformation temperature.

$\mathrm{Fe}-27.6 \% \mathrm{Ni}-0.44 \% \mathrm{C}$ martensite had also transformation twins and was deformed by twinning at room temperature, and showed strain-softening in the same manner as the martensites explained above.

Transmission electron micrographs showed three types of relationship between transformation twins and deformation twins. They were confirmed namely, (a) both twinning plane and twinning shear direction were same each other, (b) twinning plane differs from each other and twinning shear direction was same, and (c) both twinning plane and twinning shear direction were different from each other. Fig. 11 illustrates schematically these three types.

It could be considered that deformation twinning in type (a) was easily formed at the beginning of deformation in twinned martensite. Photo 16 shows an electron micrograph of deformed $\mathrm{Fe}-27.6 \% \mathrm{Ni}-0.44 \% \mathrm{C}$ martensite. In this case, the width of the bands (transformation twins) corresponded to real width of twins because the twinning plane (112) was perpendicular to the foil surface $(1 \overline{1} 0)$. Attending to the local parts marked by $B$ and $C$ at the martensiteaustenite boundary, a kink of boundary was observed, and the width of twins at the kink became about 600 $\AA$, and was larger than that of other parts and of undeformed martensite. These wide bands were produced by deformation twinning on the same twinning plane (112) in the same twinning shear direction $[11 \overline{1}]$ as the transformation twins. This means that the growth or detwinning of transformation twins takes place and combines with neighbouring twins or brings back to the matrix over an extent of several fine bands. This could be the reason why strain-softening took place at a few percent of reduction.

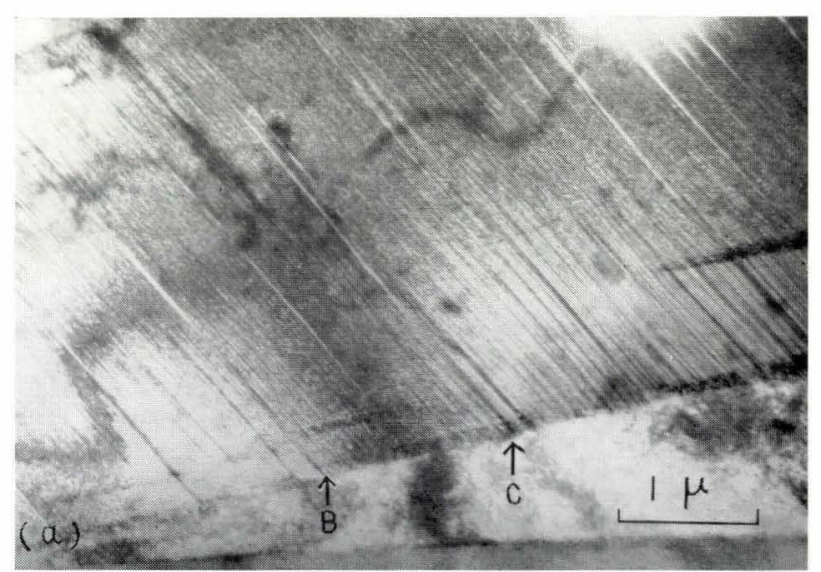

Photo 16. Transmission electron micrograph of $20 \%$ deformed $\mathrm{Fe}-\mathrm{Ni}-\mathrm{C}$ martensite, showing occurrence of detwinning 


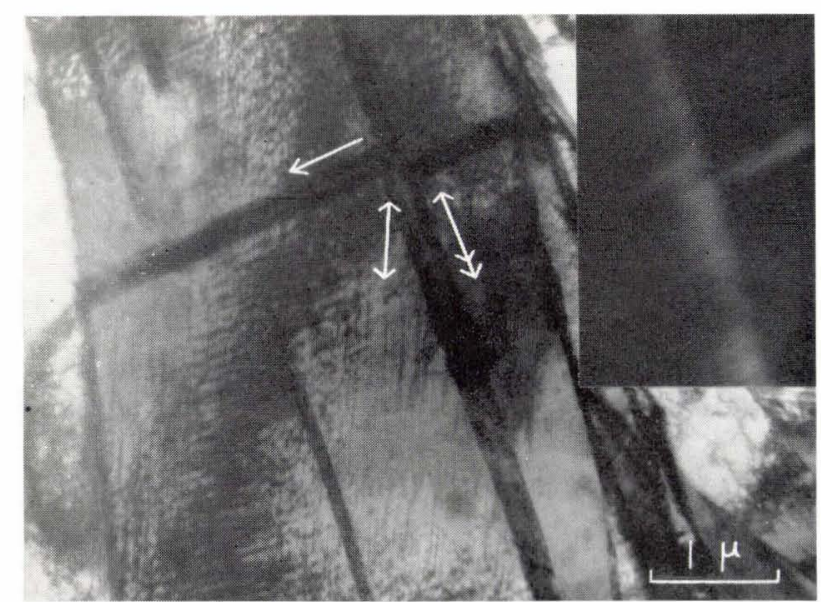

Photo 17. Transmission electron micrograph of $20 \%$ deformed Fe-Ni-C martensite, showing multiple twinning of deformation twins and transformation twins

Type of (b) and (c) can be formed at more severely deformed condition than type (a). At the intersection of twins, there is no kink for type (b) and is kinked each other for type (c). In heavily deformed martensite, several deformation twins also intersected each other, and it seemed that dislocation density somewhat increased. These multiple twinning could be the reason why strain-hardening rapidly occurred after minimum hardness with heavy reduction.

Photo 17 shows an electron micrograph of 20\%deformed martensite showing intersected deformation twins. In the micrograph, it can be found that three kinds of bands parallel to $\longrightarrow, \longleftrightarrow$ and $\longleftrightarrow$ directions. The bands indicated by $\longleftrightarrow$ were transformation twins (112), and the other two kinds of bands were deformation twins. Habit planes of these deformation twins did not correspond with any one of the surface trace of $\{112\}$ planes and moreover $\longleftrightarrow$ direction was rather near surface trace of $\{089\}$ as reported by Richman. ${ }^{22)}$ However, since dark field micrograph obtained by the diffraction spots of (211) of twins in selected area $A$ in Photo 17, showed reversal of contrast of both bands parallel to $\longrightarrow$ and $\longleftrightarrow$ directions, it could be confirmed that these bands were deformation twins also formed on twinning planes either (112),

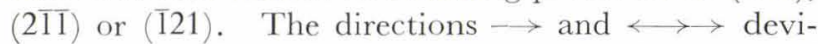
ated by about $4^{\circ}$ (clockwise) from the surface trace of twinning plane (112) and by about $11^{\circ}$ (clockwise) from (211), respectively. Therefore, it can be considered that these deformation twins are (112) [11]] and $(2 \overline{1} 1)[11 \overline{1}]$ but the habit planes are deviated from (112) and (211), respectively, due to intersecting (112) [111]-transformation twins existing densely. Fig. 12 illustrates schematically the deviation of habit plane of deformation twins. It would be expected that the deformation twins having habit planes of $\{013\},\{089\}$ and $\{0,1,13\}$ as reported by Richman ${ }^{22}$ were also $\{112\}$ type twins.

In tetragonal martensite, all possible twinning planes shown by illustration of $\{112\}$ are not equivalent and can be classified in two equivalent groups, i.e., one group is the planes having 2 or $\overline{2}$ of L-index in

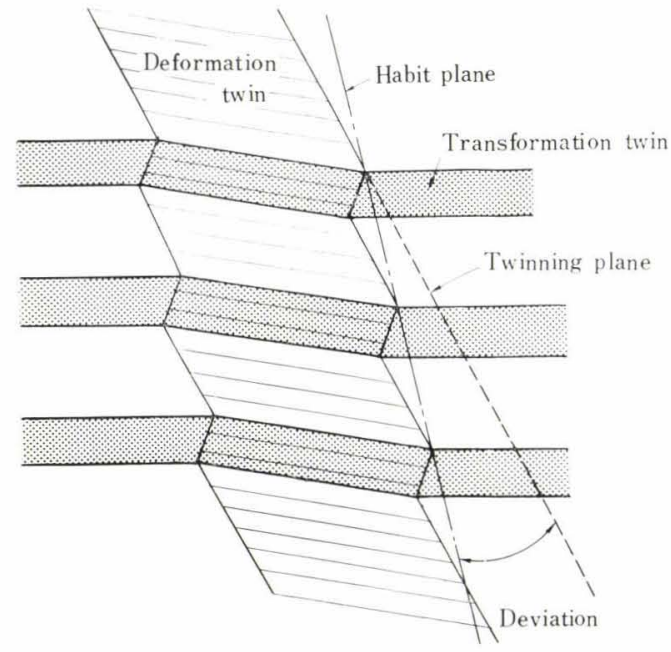

Fig. 12. Schematic illustration of habit plane of deformation twin deviated from twinning plane by transformation twins

$\{$ HKL $\}$ of $\{112\}$ and the other group is the planes having 1 or $\bar{I}$ of L-index. The former will be called "(112) group" and the latter "(211) or (121) group " in following explanations. The ratio of twinning shear is about 0.70 for (112) group and about 0.73 for (211) or (121) group for $0.4 \% \mathrm{C}$-martensite. The former is smaller than the latter. Moreover, when carbon atoms locating interstitially in ordered state in the tetragonal martensite are displaced by twinning on (211) or (121) group planes, on (2T11) plane as an example, carbon atoms at $00 \frac{1}{2}$ and $\frac{1}{2} \frac{1}{2} 0$ in matrix must be moved to positions $\frac{111}{444}$ and $\frac{113}{444}$ in twinned lattice, respectively. These positions for carbon atoms in tetragonal martensite are not stable, and carbon atoms must be moved again to the stable positions of $00 \frac{1}{2}$ and $\frac{1}{2} \frac{1}{2} 0$ within twinned lattice after twinning. On the contrary, if the twinning takes place on (112) group planes, not only the ratio of twinning shear is small, but also carbon atoms can move directly to the stable positions of $\frac{1}{2} \frac{1}{2} 0$ and $00 \frac{1}{2}$ in the twinned lattice. These considerations show that twinning on (112) group planes is easier than that on the other twinning planes in the tetragonal martensite, if external condition of shearing stress is equivalent. Therefore, it can be expected that in case of martensite transformation, transformation twins are preferentially formed on (112) group planes. Also, deformation twinning on (112) group planes would be preferred. In this work, deformation twinning can easily occur at the beginning of deformation on the plane which is the same twinning plane as the transformation twins, and takes place the detwinning of transformation twins resulting strain-softening.

$\mathrm{Fe}-32 \% \mathrm{Ni}$ martensite $(0.004 \% \mathrm{C})$ had transformation twins and was deformed by slip. Photo 18 shows an electron micrograph of $40 \%$-deformed $\mathrm{Fe}-32 \% \mathrm{Ni}$ martensite at room temperature. The illustration $\longrightarrow$ is the trace of transformation twin (121) and $\longrightarrow$ is the trace of slip plane (011) which passes through the matrix and the twin. It is observed that the traces of transformation twins are kinked by the trace of slip plane at the intersections. The slip takes place across 


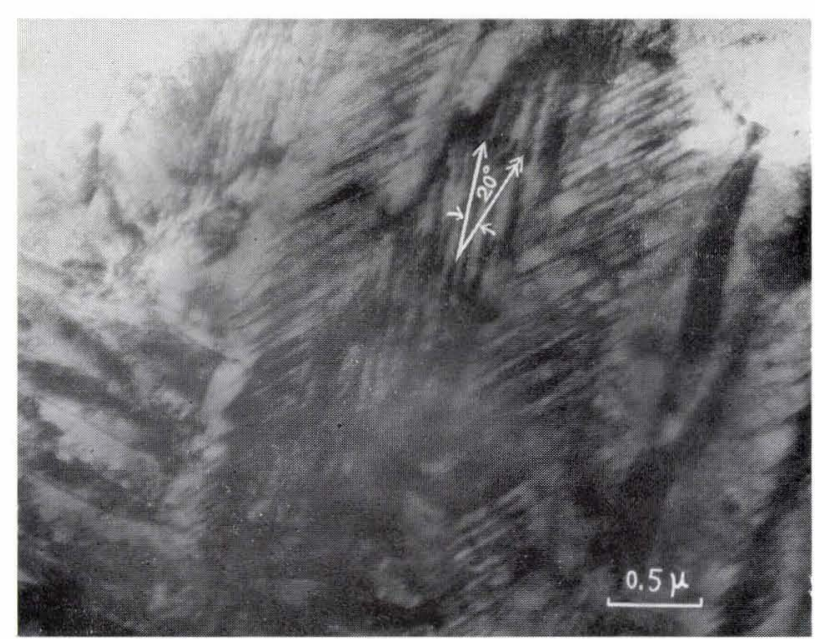

Photo 18. Transmission electron micrograph of $40 \%$ deformed $\mathrm{Fe}-32 \% \mathrm{Ni}$ martensite by slip

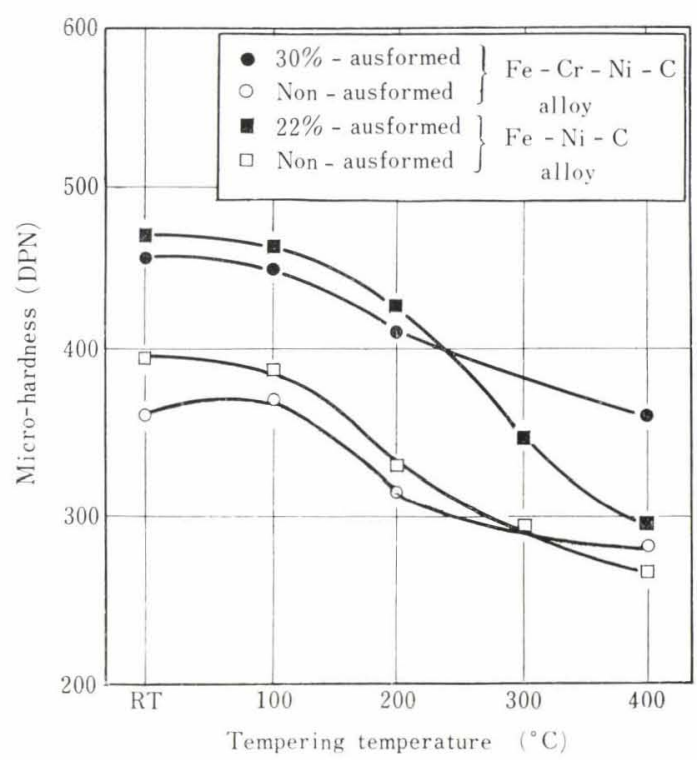

Fig. 13. Micro-hardness change of martensite and austenite in undeformed and $20 \%$-deformed $\mathrm{Fe}-\mathrm{Ni}$-C alloy with tempering temperatures

the twin boundary on the same slip plane of matrix and twin. Generally, the slip on the slip plane passing through the matrix and the twin is easiest. Even in such a easiest case, direction of slip is $[\overline{1} 1 \overline{1}]_{m}$ in matrix and is $[1 \overline{1} 1]_{t}$ in twin. Direction of slip should change at the twin boundary. Therefore, the twin boundary could be a kind of obstacles of deformation by slip, especially in the case that twin boundaries lay closely as martensite having transformation twins. However, recently, there is a leading opinion that such twin boundaries are not so considerable obstacles of deformation by slip. ${ }^{24), 25)}$ Besides, Kelly et al. ${ }^{26)}$ have reported that although the twin boundary is also one of considerable obstacles of deformation by slip, twinned martensite in $\mathrm{Fe}-\mathrm{Ni}$ alloy, for example, shown by Speich et al. ${ }^{25)}$, has lower dislocation density than the martensite having no transformation twins, because of the difference of second shear mechanism in accommodation during martensitic transformation, and hence twinned martensite does not show so parti-

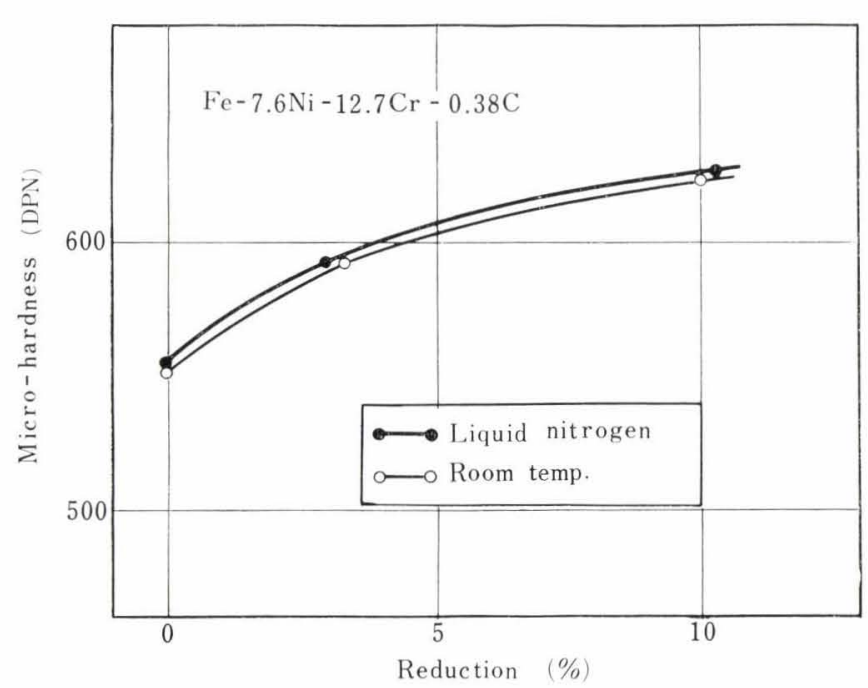

Fig. 14. Hardness change of $\mathrm{Fe}-12.7 \% \mathrm{Cr}-7.6 \% \mathrm{Ni}-0.38 \% \mathrm{C}$ martensite by rolling at two temperatures

cularly higher strength than untwinned martensite. Kellys' opinion would be reasonalbe.

Fig. 13 shows the hardness change of 20\%-deformed and undeformed Fe-27.6\%Ni-0.44\% $\mathrm{C}$ martensite and austenite with tempering temperature. The deformed martensite was harder than the undeformed throughout the range of tempering temperatures, but it was difficult to find considerable resistance to hardness decrease by tempering as which was found in the ausformed martensite. Above $200^{\circ} \mathrm{C}$, hardness was rapidly decreased. Electron micrographs showed that cementite precipitated on twin boundaries which were kinked or bent by deformation. Therefore, cementite was somewhat refined compared with that in undeformed martensite.

\section{Fe-Cr-Ni-C Martensite Having No Transformation Treins ${ }^{7), 27)}$}

$\mathrm{Fe}-12.7 \% \mathrm{Cr}-7.58 \% \mathrm{Ni}-0.38 \% \mathrm{C}$ martensite having no transformation twins but dislocations, was deformed by rolling at room temperature and at liquid nitrogen temperature. The hardness change with reduction of deformation was regularly increased at both temperatures as the same manner as strainhardening of usual metals, as shown in Fig. 14. Optical and electron micrographs did not show any information on deformation twinning in the martensite. The martensite was deformed by slip at both temperatures, and the dislocation density was increased by deformation.

By tempering of deformed martensite, cementite precipitated on the $\{110\}$ planes and the resistance to hardness decrease was not so increased as the case of ausforming.

\section{REFERENCES}

1) I. Tamura, H. Yoshimura, M. Ibaraki \& M. Tagaya : Mem. Inst. Sci. Ind. Res., Osaka Univ., 19 (1962), 67 ; Trans. JIM, 5 (1964), 47 ; J. Japan Inst. Metals, 27 (1963), 206.

2) I. Tamura, H. Yoshimura, M. Ibaraki \& M. Tagaya : Trans. JIM, 5 (1964), 97 ; J. Japan Inst. Metals, 28 (1964), 
433.

3) I. Tamura, H. Yoshimura \& M. Ibaraki : J. Japan Inst. Metals, 28 (1964), 794.

4) I. Tamura, H. Yoshimura \& M. Ibaraki: Mem. Inst. Sci. Ind. Res., Osaka Univ., 21 (1964), 63.

5) I. Tamura, M. Ibaraki \& H. Nozaki: J. Japan Inst. Metals, 29 (1965), 605.

6) I. Tamura, H. Yoshimura, N. Iwasaki \& M. Ibaraki : Mem. Inst. Sci. Ind. Res., Osaka Univ., 22 (1965), 41 ; J. Japan Inst. Metals, 28 (1964), 820.

7) I. Tamura \& T. Ohyama : J. Japan Inst. Metals, 30 (1966), 1081.

8) W. M. Justusson \& D. J. Schmatz: ASM Trans. Quart., 55 (1962), 654.

9) P. R. V. Evans \& H. O'Neill: J. Iron Steel Inst. (U.K.), 191 (1959), 34.

10) D. J. Schmatz \& V.F. Zackay: Trans. ASM, 51 (1959), 476.

11) J. C. Shyne, V. F. Zackay \& D. J. Schmatz: Trans. ASM, $52(1960), 346$.

12) E. B. Kula \& J. M. Dhosi: Trans. ASM, 52 (1960), 321.

13) V. F. Zackay, W. M. Justusson \& D. J. Schmatz: Metal Progr., 80 (1961) Sept., 68.

14) V. F. Zackay, W. M. Justusson \& D. J. Schmatz: Strengthening Mechanisms in Solids, (1962), ASM, 179.
15) M. Ibaraki \& H. Yoshimura: J. Japan Inst. Metals, 29 (1965), 1171.

16) G. Thomas, D. Schmatz \& W. Gerberrich: High Strength Materials, (1965), 251, (John Wiley).

17) P. G. Winchell \& M. Cohen: ASM Trans. Quart., 55 (1962), 437.

18) P. M. Kelly \& J. Nutting: J. Iron Steel Inst. (U.K.), 197 (1961), 199.

19) W. Pitsch \& A. Schrader: Arch. Eisenhüttenwe, 29 (1958), 485.

20) N. J. Petch: Act. Cryst., 6 (1953), 96.

21) A. J. McEvily Jr., R. H. Bush, F. W. Schaller \& D. J. Schmatz: ASM Trans. Quart., 56 (1963), 753.

22) R. H. Richman: Trans. AIME, 227 (1963), 159; Deformation Twinning, (1964), 237, [Gordon \& Beach].

23) N. N. Breyer \& N. H. Polakowski: ASM Trans. Quart., 55 (1962), 667.

24) M. Cohen: J. Iron Steel Inst. (U.K.), 201 (1963), 833.

$25)$ G. R. Speich \& P. R. Swann: J. Iron Steel Inst., 203 (1965), 480.

26) P. M. Kelly and J. Nutting: Iron Steel Inst., Special Rept. No. 93 (Physical Properties of Martensite and Bainite), (1965), 166.

27) M. Ibaraki \& H. Yoshimura: J. Japan Inst. Metals, 29 (1965), 1120. 